\title{
6. LA GARANTÍA DE LA FUNCIÓN DE CONTROL
}

PEDRO J. TENORIO SÁNCHEZ

Profesor de Derecho Constitucional

UNED 
1.-ACTUALIDAD DEL PRINCIPIO DE DIVISIÓN DEL PODER. LOS SUJETOS INTERESADOS EN EL EJERCICIO DEL CONTROL Y LA GARANTÍA DE SU POSICIÓN. A) Referencia a los cambios en la organización del Estado. A.1) En el marco del Estado-Persona. A.2) Desbordamiento del Estado-Persona. A.3) La división del poder como principio jurídico. B) Conveniencia de garantizar jurisdiccionalmente las facultades de control a los sujetos interesados en ejercerlo. B.1) El mecanismo de garantía idóneo. B.2) Control abstracto de normas y resolución de conflictos constitucionales. II.-LA CUESTIÓN EN DOS ORDENAMIENTOS EXTRANJEROS: REPÚBLICA FEDERAL ALEMANA E ITALIA. A) La cuestión en la República Federal Alemana. A.1) Los sujetos del conflicto. a) Los textos legales. b) Doctrina y jurisprudencia. A.2) El objeto de la controversia. A.3) Balance de la institución. "Derechos fundamentales" y "Derechos constitucionales". a) Sentencias en torno a la disolución de enero de 1983. b) La Sentencia de 8 de junio de 1982. B) La cuestión en la República Italiana. B.1) Planteamiento inicial, la Ley núm. 87 de 1953 y la actitud doctrinal y jurisprudencial. B.2) Los sujetos legitimados. B.3) El objeto del conflicto. C) Conclusiones. III.-LA CUESTION EN EL ORDENAMIENTO ESPAÑOL. A) Observaciones generales. B) Referencia a la regulación de los conflictos en nuestro ordenamiento. B.1) Fuentes legales y sus características. B.2) Sujetos legitimados. B.3) Objeto del conflicto. B.4) Jurisprudencia constitucional. 
Revista de Derecho Político, núm. 30, 1989, pp. 159-201

\title{
6. LA GARANTÍA DE LA FUNCIÓN DE CONTROL
}

POR

\author{
PEDRO J. TENORIO SÁNCHEZ
}

UNED

I. ACTUALIDAD DEL PRINCIPIO DE DIVISIÓN DEL PODER. LOS SUJETOS INTERESADOS EN EL EJERCICIO DEL CONTROL $Y^{*}$ LA GARANTÍA DE SU POSICIÓN

\section{A) Referencia a los cambios en la organización del Estado}

Han sido muy estudiados los profundos y numerosos cambios que ha sufrido el principio de división del poder desde los planteamientos originarios o clásicos hasta la actualidad ${ }^{1}$.

Hagamos sucinta referencia a dicha problemática, resaltando, eso sí, los aspectos relevantes a los efectos de la orientación concreta de este trabajo.

1 Aun cuando contamos entre nosotros con excelentes trabajos sobre la materia, permítasenos recordar cómo en la doctrina italiana, en la obra de DE VERGOTTINI, tiene una particular relevancia el problema del replanteamiento del principio de división del poder (en su doble vertiente "garantista" y "participativa") en las Constituciones actuales. En su estudio Indirizzo politico della difesa e sistema costituzionale (Milán 1971) encontramos la concepción del ordenamiento constitucional democrático como aquel que garantiza la alternancia en el poder y los derechos de las minorias politicas. Tras un análisis histórico del constitucionalismo británico (en Lo shadow cabinet: saggio comparativo nel rilievo costituzionale dell'opposizione nell'ordinamento britannico, Milán, Giufré, 1973), en el que la oposición aparece como institución clave en la evolución histórica del parlamentarismo en Inglaterra, formula (voz "Opposizione», en Enciclopedia del Diritto, 1980, vol. XXII), una clasificación de las formas de Estado que parte de la existencia o inexistencia de oposición garantizada para distinguir las formas democráticas de las autocráticas o totalitarias. En su Diritto Costituzionale Comparato (2."edic., Padova, Cedam, 1987), págs. 252 y ss., señala cómo la motivación garantista de la teoria de la separación de poderes continúa presente en las democracias de masas. 
Efectivamente, se han producido alteraciones considerables, tanto de hecho como jurídico-positivas. Algunas internas al propio Estado-Persona, otras que revelan el desbordamiento del propio Estado-Persona.

\section{A.1) En el marco del Estado-Persona}

Dentro del marco del Estado-Persona, de los tres poderesclásicos, el menos afectado parece ser el Poder Judicial. Recuérdese la consabida alteración de los términos en que suele plantearse el juego político en buena parte de los sistemas parlamentarios actuales: éste no discurre entre el Rey y su Gobierno, por un lado, y el Parlamento (que controlaría y legislaria), por otro, sino entre mayoría parlamentario más Gobierno, de una parte y minoría parlamentaria, de otra.

El Parlamento sigue teniendo atribuida la función de control (y en cuanto a la última expresión de la misma, la exigencia de responsabilidad política, no podría ser de otra manera), pero los interesados en ejercerlo son las minorías parlamentarias, los grupos parlamentarios, los parlamentarios individuales. $Y$ éstos, efectivamente, tienen facultades de control, entendido éste en sentido amplio ${ }^{2}$. Pero prescindiendo aquí de la posibilidad o conveniencia de aumentar semejantes facultades ${ }^{3}$, o de revisar la configuración de las existentes ${ }^{4}$, lo que queremos plantear es, sobre todo, la posibilidad de garantizar la posición de estos sujetos.

2 Sentido que adoptamos aquí y que por lo demás parece ser el más extendido en la doctrina: vid. M. ARAGON REYES: «El control parlamentario como control político", en RDP. UNED, n. ${ }^{\circ}$ 23, Madrid 1986, págs. 1 y ss., especte, págs. 24-25); F. RUBIO LLORENTE: «El control parlamentario", en Revista Parlamentaria de Habla Hispana, n. ${ }^{\circ 1}$, Madrid 1985, págs. 83 y ss., especte págs. 85 y 100; L. SANChez Agesta: Sistema Politico de la Constitución Española de 1978, EDERSA, Madrid 1987, págs. 358 a 371; A. TORRES DEL Moral: Principios de Derecho Constitucional Español, Átomo Ediciones, vol. II, págs. 223 y ss., especte pág. 235; distinto planteamiento en J. García MoRil.Lo: El control parlamentario del Gobierno en el ordenamiento español, Madrid, especte págs. 25 y ss.

${ }_{3}$ Al respecto, dice A. ToRRes del Moral, op. cit., págs. 237-238: “Tanto en la actividad legislativa como en la de control, asi en las materias más complejas como en las más simples, la mayoría vencerá normalmente a la minoría y ésta debe orientar su actuación hacia donde más eficaz pueda ser: hacia la opinión pública. Que haya más mecanismos de control no significa que haya más control. Lo único decisivo en las actuales democracias de partidos es que esas actividades de control lleguen a su verdadero destinatario: el electorado".

4 Vid., al respecto, F. RUBIo LLORENTE, en «El control parlamentario", cit., págs. 101103, quien señala que si bien cuando se trata de adoptar decisiones vinculantes, la primacía de la mayoría no puede ser ignorada, en cambio la jerarquía entre las distintas voluntades, entre los diversos grupos con presencia parlamentaria, se invierte cuando la función a desempeñar corresponde sobre todo, según la naturaleza de las cosas, no a la mayoria, sino a la minoria. Y esto es lo que sucede muy especialmente con la función de control. Aparte de una revisión en los habituales procedimientos para la fijación del orden del dia, ello obliga, por ejemplo, a dejar exclusivamente en manos de la minoría la creación de instrumentos tales como las Comisiones de Investigación. 
Dicho de esta manera: si las minorias aparecen en nuestra Constitución, en algunos casos, equiparadas a las mayorías (piénsese en los supuestos en que se exigen mayorías cualificadas, sobre todo cuando éstas son elevadas) si los grupos parlamentarios, los miembros de las Cámaras y los diversos órganos internos de las mismas tienen atribuciones ${ }^{5}$ constitucionalesórganizativas reconocidas por la Constitución o por los Reglamentos de las Cámaras, cabe preguntarse por qué no ha de existir la posibilidad de defender jurisdiccionalmente sus respectivas posiciones, una vez reconocido que, en definitiva, el Parlamento es un organo constitucional que participa del ejercicio de la soberania (incluso que participa de dicho ejercicio de manera cualificada) pero que no ostenta el monopolio de la misma. Acaso la doctrina de la inmunidad de los interna corporis del Parlamento, en la medida en que juega en favor de las mayorías, merece una cierta revisión.

\section{A.2) Desbordamiento del Estado-Persona}

Lo que llevamos dicho concierne a los poderes clásicos. Nos hemos movido, de momento, dentro del marco del Estado-Persona.

Pero es que además resulta que el Estado-Persona no sólo ofrece hoy un marco insoportablemente estrecho para la contemplación de la realidad política, sino que se presenta, como concepto, insuficiente para dar cuenta de la organización estatal constitucional-positiva. Las Constituciones actuales, entre ellas la nuestra, ofrecen un elenco de órganos constitucionales que, aunque desborde la concepción tripartita clásica, no plantea grandes dificultades en cuanto a su inserción en el marco del Estado-Persona (Tribunal Constitucional, Consejo General del Poder Judicial, Jefatura del Estado). Pero hay más. Algunos textos constitucionales actuales reconocen un pluralismo socio-político que parece dibujar una esfera organizativa que no encaja en la dualidad Sociedad-Estado (entendido este último como Estado-Persona). El reconocimiento de funciones tan relevantes como las atribuidas en las propias Constituciones a los partidos políticos -por poner un ejemplo muy claro- parece insertar a éstos en el ámbito de la «organización estatal constitucional» (concepto más amplio que el de Es-

s La legislación y la doctrina alemanas los denominan "derechos constitucionales", diversos de los "derechos fundamentales". Como quiera que entre nosotros se emplea la expresión "derechos constitucionales" en un sentido distinto (comprendiendo todos los del Cap. II del Tít. I de nuestra Constitución o, en general, los reconocidos por la Constitución), optamos por denominarlos provisionalmente «facultades" o «atribuciones" (empleando preferentemente el primer término - facultades - para designar ciertas situaciones de los parlamentarios $y$, el segundo - también preferentemente-, con referencia a las de órganos o sujetos colectivos). 
tado-Persona), y no simplemente en el ámbito de la Sociedad Civil, o ámbito de los derechos fundamentales.

Se plantea, pues, la cuestión de la garantía de la posición de estos sujetos ${ }^{6}$, su inserción en el ámbito de los mecanismos que garantizan la efectividad de las normas organizativas constitucionales.

\section{A.3) La división del poder como principio jurídico}

Es un lugar común señalar la superación del principio de «división de poderes». «Del principio tradicional de la separación de poderes, el Estado contemporáneo - dice F. BASI- ha mantenido tan sólo uno de sus puntos cardinales esenciales, que es el tendencial aislamiento del Poder Judicial respecto de los otros poderes soberanos" ${ }^{7}$. Y eso que no han faltado transformaciones en este ámbito: si por una parte dicho Poder ha visto fortalecida su posición (inversión del principio «juger l'administration c'est encore administrer», con el sometimiento exhaustivo de la actividad de la Administración Pública al control judicial: extensión de este último a la actividad materialmente administrativa de los órganos constitucionales; sustracción al Poder Ejecutivo de la función de «administración de la jurisdicción» para asignarla a un órgano constitucional ad hoc), de otra, ha visto cómo se le superponían los Tribunales Constitucionales ${ }^{8}$.

Ahora bien, en este ámbito, conviene distinguir entre la constatación de realidades de hecho y el ámbito de los principios jurídicos. Del hecho de que, como señalábamos antes, Gobierno y Mayoria Parlamentaria formen un bloque que desdibuja la división o separación Gobierno-Parlamento, no se deriva ni que las Constituciones ignoren tal principio, ni que la doctrina deba interpretarlas dando carta de naturaleza a tal hecho y reforzándolo, convirtiéndolo en un principio jurídico.

Antes al contrario, ha de recordarse que el complejo de normas organizativas constitucionales, en el Estado democrático-liberal, no están tan sólo inspiradas por criterios de racionalidad técnica, que distribuyan las

- Ello nos sitúa en un ámbito decididamente más amplio que. el del control parlamentario; o incluso el del control entendido como toda relación de poder entre organos del Estado. Por otro lado, en el presente trabajo se plantea la conveniencia de «controles juridicos" para asegurar o "garantizar» controles «institucionalizados politicos» (véase M. ARAGON REYES: “La interpretación de la Constitución y el carácter objetivado del control jurisdiccional», en $R E D C, n .{ }^{\circ} 17,1986$, págs. 85 y ss.). Nosotros aquí usamos el término garantía en un sentido impreciso (si tenemos en cuenta lo que expone el autor en págs. 98-100).

7 all principio della separaziones dei poteri", en Riv. Trim. Dir. Pubbl., 1965, pág. 91.

- Vid. L. Vacas Garcia Alos: «Aplicación de la Ley de Procedimiento Administrativo en

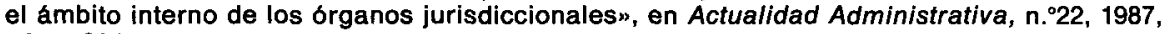
págs. 364 y ss. 
funciones para garantizar la eficacia y unidad de la acción estatal. Estos criterios están presentes igualmente en los Estados autoritarios y totalitarios. En el Estado democrático-liberal las normas constitucionales organizativas tienen una ratio garantista y participativa. Deben asegurar, aseguran, y deben interpretarse de forma que aseguren, de un lado, los derechos fundamentales $y$, de otro, la participación en el proceso de formación de la voluntad estatal de una pluralidad de órganos, algunos de los cuales pueden representar diversas fuerzas políticas o sociales, o diferentes principios de legitimación de ejercicio del poder; y, en definitiva, el sometimiento del poder al Derecho. Dicho de otra forma, este complejo normativo tiene la característica específica, en un Estado democrático liberal, de estar inspirado en un principio de «división del poder».

Las propias Constituciones establecen continuas articulaciones renovadas del mismo y la interpretación y aplicación de la Constitución ha de tenerlo presente reactualizándolo, para garantizar los valores a que está enderezado.

\section{B) Conveniencia de garantizar jurisdiccionalmente las facultades de control a los sujetos interesados en ejercerlo}

Declamos, pues, que existen sujetos internos a órganos constitucionales que no sólo son los interesados en llevar a cabo el control, sino que tienen ciertas facultades que pueden considerarse de control en sentido amplio y que, sin embargo, no ven garantizada jurisdiccionalmente su posición. Por otro lado, existen sujetos externos al Estado-Persona de los que puede predicarse una situación similar.

Parece que garantizar jurisdiccionalmente su posición, o al menos, abrir el cauce para ello, es acorde con la evolución del Estado de nuestros días y con la misma idea de Constitución. En efecto, el que algunos autores llaman Estado post-social se sigue caracterizando - al menos de momento, y parece que por mucho tiempo- por una vastísima intervención en todos los aspectos de la vida económica y social, de cuya configuración se considera protagonista. Ello exige ampliar y pulir los instrumentos de control. Visto desde otra perspectiva, cabe argumentar que sin control no puede hablarse de Constitución ${ }^{9} \mathrm{ni}$, en definitiva, de democracia: sin el control del poder no hay Constitución en sentido jurídico. Entregar las facultades

a Vid., entre nosotros, M. ARAGON ReYes, «La interpretación de la Constitución y el carácter objetivado del control jurisdiccional», en REDC, Madrid 1986, págs. 86 y ss. Concretamente pág. $86 \mathrm{y}$, del mismo autor, «El control como elemento inseparable del concepto de Constitución», en el Libro Homenaje al profesor Murillo Ferrol, CEC-CIS, Madrid 1986. 
de control a quien no está interesado en ejercerlas, o no garantizar hasta el límite posible el ejercicio de dichas facultades es renunciar, en cierta medida, a agotar las posibilidades de la Constitución.

\section{B.1) El mecanismo de garantía idóneo}

Ahora bien, ¿cuál es la vía idónea para garantizar las posiciones a que venimos refiriéndonos? Las facultades o atribuciones de que venimos hablando son «Derecho Constitucional objetivo subjetivado», puro reflejo de normas organizativas, pertenecen al ámbito de la organización estatal, a diferencia de los derechos fundamentales, derechos subjetivos, que encuentran su fundamento en las normas constitucionales y pertenecen al ámbito de las relaciones entre la Sociedad y la organización estatal.

Por supuesto, cabe la posibilidad de que el ordenamiento fortalezca la posición de estos sujetos legitimándolos, por ejemplo, para interponer recurso de inconstitucionalidad, o que forzando el recurso de amparo, estos sujetos puedan ver protegida su situación jurisdiccionalmente.

Pero como de lo que se trata es de indicar cuál es el cauce idóneo para proteger su posición en cuanto elementos del conjunto de mecanismos de cheks and balances que establece la Constitución, parece que, entre las competencias que encontramos atribuidas a Tribunales Constitucionales como el español, el alemán o el italiano, la más idónea para judicializar la garantía de estas posiciones jurídicas resulta ser, en principio, la competencia para la resolución de los conflictos entre órganos constitucionales. Es éste un mecanismo que parece especialmente instituido para garantizar las normas constitucionales organizativas ${ }^{10}$ (aun cuando éstas hayan de aplicarse también con motivo del ejercicio, por parte del Tribunal Constitucional, de otras competencias).

\section{B.2) Control abstracto de normas y resolución de conflictos constitucionales}

Es esta una competencia, en principio, sustancialmente distinta del control abstracto de normas. Más aún, originariamente, estas dos competencias que hoy confluyen en los Tribunales Constitucionales alemán (fe-

10 Vid. A. Pizzorusso, voz “Conflitto», en Novissiomo Digesto Italiano (aggiornamento), Turín 1981, págs. 366-367 y nota 1. Destaca la conexión con las normas organizativas, asi como el parentesco de esta competencia con la justicia constitucional como «Staatsgerichtsbarkeitw. 
deral), italiano o español, representaron dos maneras diversas de plantear la justicia constitucional ${ }^{11}$.

a) En el sistema Kelseniano (de la Verfassungsgerichtsbarkeit) la actividad del juez constitucional no queda comprendida dentro del concepto de jurisdicción (entendida como aplicación de la norma a los hechos concretos). Al Tribunal Constitucional se le atribuye la competencia de controlar, con la Constitución como parámetro, la validez de la Ley. Esto es, se le encomienda efectuar un control de mera compatibilidad lógica, que en modo alguno incluye el examen de los hechos y de los intereses concretos que la ley regula (examen que se atribuye a la jurisdicción ordinaria). Valoración de los hechos y valoración de la constitucionalidad de las leyes no forman parte de un inescindible proceso cognoscitivo, sino que son considerados momentos distintos y separados, atribuidos a órganos diversos. Con ello se compadece que las decisiones de los Tribunales Constitucionales tengan eficacia erga omnes.

b) La Staatsgerichtsbarkeit, o jurisdicción constitucional como resolución de conflictos entre órganos supremos, tiene por objeto la resolución de controversias concretas. Por consiguiente, puede reconstruir y valorar los hechos, y puede aplicar normas de cualquier grado (siempre que sean constitucionales). Su actuación es jurisdiccional, similar a la del juez civil o penal. Con ello se compadece que sus sentencias tengan sólo eficacia inter partes.

No obstante estas profundas diferencias, existen posibles superposiciones o puntos de contacto, de un lado; y de otro, un acercamiento en la práctica jurisprudencial de los TT.CC. que tienen atribuidas estas competencias.

- Como puntos de contacto o superposiciones mencionaremos dos supuestos: impugnación a instancia del Estado central de las leyes de los Estados Miembros (y viceversa), cuando tal impugnación esté condicionada por un «interés al recurso» (similar al genéricamente exigido por las leyes procesales) y conflicto que tenga por objeto un acto del procedimiento le-

1 Vid. P. Chuz VILLALón: La formación del sistema europeo de control de constitucionalidad (1918-1939), CEC, Madrid 1987, págs. 127-171; F. J. GARCla RoCA: El conflicto entre órganos constitucionales, Tecnos, Madrid 1987, págs. 21 y ss.; M. MAzzıotrı: / conflitti di attribuzione fra i poteri dello Stato, vol. Il. Giuffré, Milán 1972, págs. 5 y ss.; G. Volpe: L'ingiustizia delle leggi. Studi sui modelli di giustizia costituzionale, Giuffré, Milán 1979, págs. 165 y ss., especialmente págs. 166, 174, 176; P. PÉrez-Tremps: Tribunal Constitucional y Poder Judicial, CEC, Madrid 1985, págs. 41 y ss.; A. PIzzorusso, en Commentario della Costituzione a cura di G. Branca, sub. art. 134, Zanichelli, Foro Italiano, Bologna-Roma 1981, págs. 27 y ss. 
gislativo, cuya eventual anulación pueda suponer inconstitucionalidad de la ley.

- En cuanto al acercamiento en la práctica jurisprudencial, se produce en doble dirección: asimilación del control abstracto a la técnica del conflicto (a.1) y viceversa (b.1).

a.1) Algún autor ha advertido una adulteración de la técnica de examen de constitucionalidad de las leyes (sobre todo como consecuencia del intento de realización o aplicación del principio de igualdad sustancial), a través del llamado control de razonabilidad (ragionevolezza) de las leyes. Tal técnica supone extender la competencia del TC hasta el examen de los hechos que son fundamento de la ley, pasando de un control de «razonabilidad" de la ley a uno de «justificabilidad" (giustificatezza) de la misma, a la indagación, más allá de la «irrazonabilidad», de la injusticia de la ley ${ }^{12}$.

b.1) Por cuanto se refiere al acercamiento de la técnica del conflicto a la del control abstracto, mencionaremos dos supuestos: en primer lugar el TC, al conocer de un conflicto, puede no entrar en la valoración de los hechos de un modo total, reconociendo a los órganos constitucionales una facultad de prognosis en la que el TC no debe sustituirlos. Puede que al hacerlo dicte sentencias "salomónicas", pero tal opción es acorde con la configuración de estas competencias -que tiene tan sólo, en principio,

12 Ya aludimos anteriormente a la diferencia entre la Verfassungsgerichtsbarkeit y la Staatsgerichtsbarkeit. Para G. VOLPE, op. cit., el sistema italiano, que se inscribe en el primer modelo (págs. 249 y ss.), en la práctica jurisprudencial, se ha visto alterado por un tipo de examen de las leyes que ha deslizado el sistema hacia el segundo modelo mencionado (pág. 264). Para el autor (págs. 280-281), el Tribunal realiza un control de inconstitucionalidad propio de un sistema abstracto, cuando indaga: a) la incompatibilidad lógica o «ilegitimidad" de la norma con cualquier parámetro constitucional (distinto del principio de igualdad-razonabilidad); b) el carácter ilógico (incoherencia, incongruencia, carácter contradictorio, etc.) interno de las disposiciones que contiene la ley examinada: se trata de vicios lógicos deducibles por vías internas al conjunto legislativo examinado, que violan el art. 3, apartado 1 de la Constitución italiana (irrazonabilidad de las diversificaciones o equiparaciones de tratamiento); c) ilogicidad-irrazonabilidad de los contenidos de la ley, en cuanto contemplan discriminaciones o equiparaciones no justificadas por la intención de alcanzar otras finalidades establecidas constitucionalmente. En los tres supuestos el Tribunal suprime vicios logicos de las normas. En los dos últimos casos, en concreto, vicios de «irrazonabilidad» compatible con el sistema de control abstracto.

Al margen de estas hipótesis, esto es, cuando la racionalidad o razonabilidad de la ley (en relación con el principio de igualdad, en particular) se indaga empleando como parámetro datos extranormativos, provenientes de un directo y autónomo análisis y valoración de las situaciones históricas, o de la propia "visión de las cosas", entonces el Tribunal está examinando la incidencia de la ley en el ámbito de la realidad histórica y del horizonte ideológico, está entrando a examinar la giustificatezza o la giustizia de la ley, lo que es propio del sistema de la Staatsgerichtsbarkeit (que previamente había naufragado, a la altura de la posguerra).

Por lo demás, este autor subraya que las únicas operaciones de este género que permite el sistema se fundarian en el art. 32 de la Constitución Italiana, y que deberian moverse dentro de lo preceptuado por éste (vid. págs. 282 y ss.). 
carácter alternativo a la resolución del conflicto en sede política- y con la naturaleza política del conflicto y de los órganos eventualmente implicados.

Un ejemplo lo ofrece la Sentencia del TC Federal Alemán (TCFA) de 16 de febrero de $1986{ }^{13}$ relativa a un posible efraude a la Constitución» (al art. 68 de la L.F. Bonn) por cuanto el Canciller, que contaba con mayoria en el Bundestag, provocó la denegación de una cuestión de confianza para posibilitar la disolución y consiguiente convocatoria de elecciones; el TCFA, sin perjuicio de advertir que Presidente, Bundestag y Canciller estaban vinculados por la ratio del art. 68 LFB (L.F. Bonn), reconocía que el supuesto de hecho se daba cuando existieran dificultades extraordinarias para desarrollar las labores parlamentarias, y que los tres órganos mencionados tenían un margen de apreciación al respecto: vinculados por la ratio, les reconocía la prognosis.

El segundo supuesto entraña un ejercicio de esta competencia del TC que probablemente la desnaturaliza ${ }^{14}$. Se trata del caso de la Sentencia del TC italiano (TCl) 14/65: un Reglamento de una Región contrario al Estatuto Especial, se consideró viciado de incompetencia del Estado; se entendió que había asumido concretamente la competencia de dictar normas de rango constitucional (que son las que pueden modificar los Estatutos).

Todo ello hace indispensable aproximarse a las regulaciones que ofrece el Derecho Positivo y a la práctica jurisprudencial.

\section{LA CUESTION EN DOS ORDENAMIENTOS EXTRANJEROS: R.F.A. E ITALIA}

Si volvemos nuestra mirada a dos de los ordenamientos constitucionales que actualmente parecen más próximos al nuestro ${ }^{15}$, detectare-

13 Posteriormente (apdo. II.A.3.a) nos referiremos con más detenimiento al caso.

14 L. ELIA: «Dal conflitto di attribuzione al conflitto di norme», en Giur. Cost., 1965, págs. 145 y sS., señala que se basa en un razonamiento apodíctico. S. Grassı: // giudizio costituzionale sui conflitti di attribuzione fra Stato e Regioni e fra regioni, Giuffré, Milán 1985, págs. 109 y ss., describe el caso, incluyendo la Sentencia entre las de orientación centralizadora. En sentido más descriptivo que crítico, G. Zarebelsky: La Giustizia Costituzionale, Bologna, II Mulino, 1977, págs. 199-200.

15 La institución de los conflictos entre órganos constitucionales tiene en Austria un desarrollo muy limitado si lo comparamos con el de la República Federal Alemana. El Tribunal Constitucional Austriaco: a) interviene cuando entre el Tribunal de Cuentas y el Gobierno Federal o algún Ministerio federal de un land hay divergencias de criterio sobre la interpretación de los preceptos legales que regulan la competencia del Tribunal de Cuentas (art. 36.a) de la Ley reguladora del Tribunal de Justicia Constitucional, de 1953); y b) resuelve «...las controversias entre la Volksanwaltschaft (ombudsman colegiado austriado) y el Gobierno federal, un ministro federal, o el Gobierno de un land, sobre la interpretación de las disposiciones legislativas que regulan la Volksanwaltschaft (art. $36 . g$ de la Ley últimamente mencionada). Vid. E. Alonso GaRCIA: «El Tribunal Constitucional Austriaco», en El Tribunal Constitucional, vol. I, IEF, Madrid 1981, págs. 429-430; Theo OHLINGER: Legge sulla Corte Costituzionale austriaca, Cedeur-Centro Editoriale Europeo, Firenze 1982, págs. 27, 29-30, 65, 96-99. 
mos no sólo en la doctrina, sino también en el Derecho legislado y en la jurisprudencia constitucional, esta tendencia a potenciar y garantizar los mecanismos de control, aun cuando las dificultades dogmáticas no son escasas.

\section{A) La cuestión en la República Federal Alemana ${ }^{16}$}

\section{A.1) Los sujetos del conflicto}

\section{a) Los textos legales}

En la República Federal Alemana, el art. 93.1.1 de la Ley Fundamental de Bonn (en adelante, L.F. Bonn) establece la competencia del Tribunal Constitucional Federal para decidir sobre la «interpretación de la Ley Fundamental respecto a las controversias sobre el alcance de los derechos ${ }^{17} \mathrm{y}$ deberes de un órgano federal supremo o de otras partes interesadas dotadas de derechos propios por la presente Ley Fundamental o por el Reglamento interno de un órgano supremo de la Federación» ${ }^{18}$.

El texto de este artículo se repite en el art. 13.5 de la Ley reguladora del Tribunal Constitucional Federal (en adelante LTCF). En cambio, el art. 63

16 Vid. A. J. Porras Nadales: "Conflictos entre organos constitucionales del Estado y principio de división de poderes", en REP (Nueva Época), n. ${ }^{\circ} 52,1986$, págs. 19 y ss.; F. J. Garcla Roca, op. cit., págs. 25 y ss.; L. MANZANARES SAMANiEgo: “El Tribunal Constitucional Federal Alemán», en El Tribunal Constitucional, cit., vol. II, Madrid 1981, págs. 1551-1571; M. Mazziotti: / conflitti di attribuzione fra i poteri dello Stato, 2 volúmenes, Milán 1973; T. RITTERSPACH: Legge sul Tribunale Costituzionale della Reppublica Federale in Germania, CedeurCentro Editoriales Europeo, Firenze 1982.

${ }_{17}$ Por supuesto, la atribución de derechos a los órganos ha suscitado debate doctrinal. Hasta donde hemos alcanzado a ver, algunos autores lo explican como asunción transitoria de derechos que continuarian siendo, en último análisis, los mismos de la persona juridica. Otros, subrayan como punto de partida la concepción del Estado como organización articulada en su interior: para quienes sostienen esta postura existe una pluralidad de brganos entre los que tienen lugar relaciones juridico-constitucionales, que pueden desplegarse en (o contemplarse como) derechos y obligaciones. Esta atribución constitucional y la propia institución de los conflictos «subjetivizan» a los órganos.

Utilizaremos, en cualquier caso, la expresión «derechos constitucionales» sólo para el caso de la República Federal Alemana.

18 Esta competencia no habla sido establecida en la Constitución de Weimar, que habia limitado al ámbito interno de los Lander la posibilidad de resolución judicial de conflictos de este tipo (art. 19, apdo. 1). Según el art. 99 de la Ley Fundamental de Bonn, la decisión sobre los conflitos constitucionales en el interior de un Land puede ser atribuida al Tribunal Cons- 
de esta Ley introduce alguna matización: «demandante o demandado pueden ser sólo: El Presidente Federal, la Dieta Federal, el Consejo Federal, la Comisión prevista en el art. 45 de la Ley Fundamental, el Gobierno Federal y las partes de tales órganos que están dotadas de propios derechos por la Ley Fundamental o por los reglamentos internos de la Dieta Federal o del Consejo Federal».

Hagamos algunas observaciones sobre estos preceptos. Ante todo, el elenco que ofrece este precepto - Presidente Federal, Bundestag, Bundesrat, Gobierno Federal- no es exhaustivo, pues a pesar de la expresión «sólo», empleada al principio, hay un reenvio a otras fuentes.

Por otro lado, el art. 63 LTCF introduce una restricción a lo señalado en el art. 93.1.1 L.F. Bonn, en cuanto alude a los Reglamentos del Bundestag y del Bundesrat, y no a los de cualquier órgano federal. Tal limitación, sin embargo, no parece relevante: el Canciller Federal y los Ministros pueden apoyarse directamente en el art. 93.1.1 L.F. Bonn para ejercitar sus propios derechos.

Retengamos cómo legalmente en la República Federal Alemana pueden, pues, ser parte en conflicto no sólo órganos constitucionales, sino partes de esos mismos órganos.

\section{b) Doctrina y jurisprudencia}

Pero la doctrina ha ido aún más lejos, llegando a la inclusión, en el círculo de los sujetos legitimados, de sujetos externos al Estado-Persona. Resumamos la argumentación al respecto.

El punto de partida es la observación de que los derechos de que habla el art. 93 de la L.F. Bonn no son simples derechos que encuentran su fundamento en normas constitucionales, sino Derecho Constitucional subjetivado. $Y$ que hablar de derechos esgrimibles en el seno del EstadoPersona no es posible, por lo que el punto de referencia de la institución de los conflictos es la Constitución, la organización constitucional estatal, el Estado si se quiere, pero no como persona jurídica unitaria, sino como organización. Es más, el reconocimiento de «partes de órganos» como par-

titucional Federal por Ley del Land correspondiente. Solamente Schleswig-Holstein ha hecho uso de esta facultad. Los restantes Lander han establecido Tribunales Constitucionales propios. 
tes en conflicto supone renunciar no ya sólo a la cohesión de la persona jurídica Estado, sino a la propia cohesión de la eventual personificación del "órgano estatal». De modo que la capacidad para ser parte se relativiza, no tiene carácter absoluto, sino que se deriva del reconocimiento de «derechos constitucionales» por parte de la Constitución. Ha de contemplarse entonces la posibilidad de capacitar a los diversos elementos que participan en las relaciones constitucionales, atender a criterios materiales más que a criterios formales.

Pues bien, el Tribunal Constitucional Federal ha aceptado el carácter relativo de la capacidad para ser parte. No reconoce a las mayorias o minorias variables dicha capacidad, pero si a los grupos permanentes del Parlamento, conforme al Reglamento interno. También a algunas Comisiones, al Presidente de la Dieta Federal y al simple parlamentario, si éste se opone a una disposición que perjudique a su status de diputado, es decir, a su posición jurídica reconocida por la Constitución.

Igualmente, en su jurisprudencia, el Tribunal de Karlsruhe ha reconocido a los partidos capacidad para ser parte, considerándolos «unidades organizadas sin las cuales es imposible el desarrollo de las elecciones», “instituciones constitucionalmente necesarias», e incluso «órganos constitucionales" (aunque no órganos del Estado, como destaca la doctrina, que incluso ha criticado su supuesto carácter de «órganos constitucionales").

Por lo demás, el Tribunal Constitucional Federal ha rechazado los conflictos planteados por simples ciudadanos. Los conflictos, el art. 93.1.1 de la Ley Fundamental, se refieren al funcionamiento de la organización estatal, mientras que la relación entre pueblo y "estatalidad organizada" tiene lugar a través de los derechos políticos fundamentales, en particular, por medio del derecho al sufragio.

En lo concerniente a la legitimación pasiva, el Tribunal Constitucional Federal ha sido muy pragmático, siendo difícil inferir una línea clara (así, por ejemplo, se ha considerado legitimado pasivamente el gobierno de un Land, fundándose en su cooperación en la fase de iniciativa del acto que dio lugar al conflicto). En todo caso, la jurisprudencia parece fundarse en la idea de que sería necesaria la inclusión en el procedimiento tan sólo del principal responsable del acto que provoca el conflicto.

Según el art. 65 LTCF, junto al demandante y al demandado, pueden, en cualquier estado del procedimiento, Intervenir otros que tengan derechos de los referidos en el art. 63, cuando la decisión sea relevante también para la delimitación de las respectivas competencias.

Por último, ha de destacarse que de la regulación parece despren 
derse la posibilidad de que una parte de un órgano ejercite derechos del órgano, incluso frente a este último.

\section{A.2) El objeto de la controversia}

El fenómeno paradigmático que provocaría el conflicto o, dicho en ótros términos, el objeto de la controversia, sería la violación de un derecho a través de una medida. La noción de «medida» se interpreta ampliamente: actos de hecho, actos jurídicos singulares o normas; la misma ley puede incluirse (aun cuando no puede ser declarada su nulidad por esta vía); el conflicto se admite no sólo cuando se alega la asunción indebida de la competencia de otro órgano, sino también cuando se alega que un órgano, actuando dentro de los límites formales de la competencia, aprueba un acto cuyo contenido puede resultar lesivo; la violación del derecho de otro organo puede tener lugar por medio de una omision (el Tribunal ha considerado como tal, por ejemplo, la falta de presentación de un Tratado internacional al Bundestag).

En cuanto al objeto de la decisión del Tribunal que resuelve el conflicto, el art. 67 LTCF establece que: «el Tribunal Constitucional Federal declara en su decisión si la acción o la omisión impugnada viola un precepto de la Ley Fundamental. El precepto debe ser precisado. El Tribunal Constitucional Federal puede igualmente resolver en la parte dispositiva de la decisión una cuestión de derecho relevante para la interpretación de la norma de la Ley Fundamental de la que depende la declaración del primer inciso" 19.

\section{A.3) Balance de la institución. "Derechos fundamentales» $y$ "Derechos constitucionales"}

Por lo demás, no ha de exagerarse la importancia del instituto en estudio. Es cierto que el poco uso del mismo hace dudar de que se trate de un mecanismo indispensable o esencial para el Estado de Derecho.

El Tribunal Constitucional Federal se pronunció sobre la naturaleza de los conflictos en dos Sentencias de los años 1952 y 1953. Las sentencias posteriores - no muchas - se fundan en los principios establecidos en es-

19 En un procedimiento de conflicto no puede ser declarada ineficaz una disposición ni declarada nula una Ley (T. RITTERPACH, op. cit., pág. 115). 
tos primeros casos ${ }^{20}$. No ha tenido, pues, nuestro instituto un gran desarrollo desde el punto de vista estadístico, aunque si ha dado ocasión a algún proceso espectacular: los suscitados por la disolución del Parlamento dispuesta por Cartens el 6 de enero de 1983, por medio de una aplicación del art. 68 de la Ley Fundamental, que la oposición consideró fraudulenta. Vamos a detenernos en este supuesto ${ }^{21}$ y en otro más para intentar ilustrar el funcionamiento de la institución.

20 T. RITTERSPACH, op. cit., pág. 54.

21 Recordaremos, ante todo, los hechos y la controversia política envolvente: el 17 de septiembre de 1982 el Canciller Helmut Schmidt, que encabezaba una coalición de socialdemócratas y liberales, perdía su propia mayoria en el Bundestag como consecuencia de la separación de los liberales de la coalición y del Gobierno. Todas las fuerzas politicas urgian la convocatoria de nuevas elecciones, pero mientras el Canciller quería llegar a ellas por medio del art. 68 L.F. Bonn, la oposición democristiana quería conseguir primero la formación de un nuevo Gobierno, por medio del art. 67 L.F. Bonn (moción de censura constructiva) argumentando con la conveniencia de resolver antes de las elecciones, en breve plazo, las cuestiones urgentes (aprobación del presupuesto, nueva estrategia de defensa militar). Esta operación se llevó a cabo, y el nuevo Canciller (Kohl) anunció su propósito de convocar elecciones en el siguiente mes de marzo (es decir, a los seis meses aproximadamente de la moción de censura constructiva). El dilema que se planteaba consistía en dilucidar si la disolución debia producirse por medio del art. 63 L.F. Bonn - tesis de los socialdemócratas, ahora en la oposición- o a través del art. 68 L.F. Bonn (tesis del Gobierno).

En el fondo de la polémica estaba la intención de ambos partidos de beneficiarse del llamado "efecto Canciller", es decir, de la tendencia del electorado a favorecer al partido del Canciller. La única vía posible para los socialdemócratas era conseguir la mayoria relativa en caso de aplicación del art. 63 (en un momento anterior, antes de la moción de censura constructiva, les hubiera convenido la disolución por la via del art. 68).

Parece conveniente detenerse mínimamente en la regulación constitucional en cuestión. La Ley Fundamental de Bonn no prevé ni la autodisolución ni la libre disolución, solamente contempla dos supuestos de disolución: uno, tras las elecciones generales (o tras la dimisión o muerte del Canciller), sería el del art. 63; otro, durante la legis(atura, cuando el Canciller plantea la cuestión de confianza y el Bundestag no se la concede por mayoria absoluta, sería el caso del art. 68. Ahora bien, la lógica de fondo que preside ambos casos parece ser -dice S. Ortino- la misma: un Parlamento que pueda constituir una mayoria absoluta para apoyar a un Canciller, no puede ser disuelto anticipadamente. Así pues, en la situación existente en aquel momento, para conseguir la disolución anticipada había de procederse a una votación ficticia.

Y así se hizo, empleando la vía del art. 68 de la Ley Fundamental: presentada la cuestión de confianza por el Canciller, los socialdemocratas votaron en contra y los liberales y democristianos se abstuvieron; el 6 de enero de 1983, el Presidente Cartens firmo el decreto de disolución y al dia siguiente se convocaban elecciones para el 6 de marzo. Pero antes de esa fecha, el Tribunat de Karlsruhe hubo de resolver dos recursos planteados por dos electores (Sentencias de 11 y 12 de enero de 1983) y cuatro conflictos de atribuciones formuladas por cuatro diputados.

Vid. F. SAINz MORENO: "Acerca de la disolución del Bundestag el 7 de enero de 1983", en REDC, año $3, n .^{\circ} 8,1983$, págs. 209 y ss., donde está traducida la sentencia de 16 de febrero de 1983; S. Ortino: Diritto costituzionale. Storia, Ordinamento, Teoria, Florencia 1985, págs. 173 y ss., quien estudia con más detalle las circunstancias. E. VIRGaLA ForuRia: "La responsabilidad política del Gobierno en la República Federal de Alemania: la moción de censura constructiva y las mociones de reprobación», en REDC, 21, Madrid 1987, págs. 99 y ss. 
a) Sentencias en torno a la disolución de enero de 1983

La Sentencia de 11 de enero de 1983 declaró la inadmisibilidad de un recurso planteado por un elector que solicitaba medidas cautelares para impedir que el Presidente disolviese el Bundestag. Una vez disuelto éste, el Tribunal interpretó la solicitud en el sentido de pretensión de declaración de nulidad. El Tribunal declaró que el ordenamiento no preveía medidas cautelares del género solicitado y que del art. 38 de la Ley Fundamental no se desprendía el derecho de cualquier elector a exigir que el Bundestag no se disolviera por la vía del art. 68 de la Ley Fundamental.

La Sentencia de 12 de enero de 1983 declaró igualmente la inadmisibilidad del recurso presentado por otro elector: esta disolución -entiende el Tribunal- incide sobre el Bundestag y sobre sus miembros, pero no incide de manera directa, en sentido jurídico, sobre cada ciudadano individualmente considerado. Rechazó el Tribunal igualmente la pretendida legitimación con base en los arts. 41.2 y 48 (ambos de la LTCF), que preven la legitimación de los electores (en número mínimo de 100, requisito que se cumplía en este caso) para instar un procedimiento para controlar la regularidad de las elecciones, por entender que semejante procedimiento se referia al control sucesivo - y no preventivo- de las elecciones.

En cambio, el Tribunal consideró admisibles los conflictos suscitados por cuatro diputados, los cuales, fundándose en los arts. 93.1 L.F. Bonn, 13.5 LTCF y 63 a 67 LTCF, pretendian que se declarase que la resolución del Presidente Federal de 6 de junio de 1983 violaba el art. 68 de la Ley Fundamental de Bonn y dañaba directamente el estatuto de los diputados, garantizado a los reclamantes por el art. 38, apdo. 1 de la Ley Fundamental (dos recurrentes solicitaban también que la declaración se extendiese además al acto de convocatoria de las elecciones).

Los recurrentes sostenían que la utilización del art. 68 de la Ley Fundamental estaba viciada (el Canciller disponia de una mayoria para continuar) porque perseguía un fin distinto del de la norma (que sería la formación de un Gobierno estable); dañaba además su derecho a continuar siendo diputados durante cuatro años (art. 39 L.F. Bonn).

El Tribunal reconoció que, además de los requisitos formales contenidos en el art. 68 L.F. Bonn, este artículo tenía una ratio igualmente vinculante; según el Tribunal, este precepto no permite a un Canciller que tenga mayoría indudable en el Bundestag provocar una respuesta negativa a una votación de confianza con la exclusiva finalidad de lograr una disolución del Bundestag; pero, por otro lado, está justificada la disolución por el hecho de que en el curso de la legislatura hayan surgido dificultades extraordinarias para desarrollar los trabajos parlamentarios. La disolución presupone - según el Tribunal- el acuerdo entre el Bundestag, el Canciller y el Presidente, los cuales, aun estando vinculados a la ratio del art. 68 
(L.F. Bonn), tienen un margen de apreciación, les corresponde a ellos hacer la prognosis o valoración al respecto.

Por ello, entre otras razones ${ }^{22}$, el Tribunal considera la disolución conforme a lo establecido en la Ley Fundamental de Bonn.

Resaltemos cómo los electores, titulares de derechos fundamentales, no pueden suscitar conflicto. Sí, en cambio, los miembros de la Cámara, en defensa de su status. Esta distinción entre derechos fundamentales y derechos constitucionales aparece en el otro caso a que vamos a referirnos.

\section{b) La Sentencia de 8 de junio de 1982}

Es el caso resuelto por la Sentencia de 8 de junio de 1982. Un diputado fue amonestado por el Presidente en funciones del Bundestag; tras reclamar ante la Junta de Portavoces y la Presidencia del Bundestag, que no revocaron la amonestación, formuló reclamación ante el Tribunal. El Tribunal, en su Sentencia, rechaza que la libertad de palabra del Diputado (como tal) descanse en el art. 2.1. ("Todos tienen derecho al libre desenvolvimiento de su personalidad...") o en el 5.1. («Todos tienen derecho a expresar y difundir libremente su opinión...”) ambos de la Ley Fundamental. La libertad de palabra del Diputado descansa en el art. 38, pfo. 1, inciso 2, L.F. Bonn («Los diputados serán representantes del pueblo en su conjunto...") y goza del privilegio de la inmunidad del art. 46.1 (L.F. Bonn) que no concierne a la libertad de expresión del art. 5. Pero, a la inversa, es posible que las expresiones de un diputado atenten contra el orden del Parlamento y sean sancionadas por el Presidente, «aunque tales expresiones se encuentren dentro de los límites de la libertad de expresión del art. 5 de la Ley Fundamental». "La libertad de palabra del Diputado en el Parlamento no es la libertad de todo ciudadano frente al Estado garantizada por el art. 5.1. de la Ley Fundamental, sino una competencia irrenunciable de la democracia para la realización de las tareas parlamentarias" ${ }^{23}$.

${ }_{22}$ Quizás sea interesante recoger aquí cómo el Tribunal rechaza la tesis según la cual el Gobierno surgido por medio de una moción de censura constructiva, tendría necesidad de la legitimidad de nuevas elecciones; tesis que supone contemplar la República Federal Alemana como una democracia plebiscitaria - dicho sin connotación peyorativa alguna-, en la que las mayorias parlamentarias y el Gobierno provendrían de un único acto: las elecciones generales (postura que sostuvo el Vicepresidente del Tribunal Constitucional, Zeidler). Un buen ejemplo de deslinde entre la contemplación jurídico-constitucional y la sociológica o política. $Y$ un rechazo importante de una tesis que guarda cierto parentesco con las posiciones doctrinales que tienden a dar carta de naturaleza (en el ámbito jurídico-constitucional), más aún de la que ya tiene, al fenómeno del desplazamiento de la función legislativa hacia el Ejecutivo.

${ }_{23}$ Vid. el comentario que hace a esta Sentencla F. SAINZ MORENO en B.J.C., n. ${ }^{\circ} 20$, págs. 1120 a 1126. Otro conflicto que tuvo singular trascendencia, y que enfrentó a una Comisión de investigación con el Gobierno Federal (y los Ministros de Hacienda y Economía) fue el del caso Flick. La Sentencia, de 17 de junio de 1984, publicada en B.J.C., n. ${ }^{\circ} 45$, págs. 107 y ss. 


\section{B) La cuestión en la República Italiana ${ }^{24}$}

\section{B.1) Planteamiento inicial: La Ley $n .^{\circ} 87$ de 1953 y la actitud doctrinal y jurisprudencial}

En Italia, la competencia para resolver conflictos entre Poderes del Estado, atribuida al Tribunal Constitucional por el art. 134 de la Constitución italiana, fue desarrollada por una ley - la $n .^{\circ} 87$ de 1953- poco detallada, inspirada en la tripartición clásica de poderes y centrada, en cuanto al objeto del conflicto, en la noción de vindicatio potestatis. $Y$ así fue interpretada y aplicada - poco aplicada- en un principio.

En la laberíntica regulación del instituto (no claramente deslindado de los conflictos entre Administración y Justicia) cabe destacar, en lo relativo a los sujetos legitimados, el art. 37 , apdo. 1 , y en cuanto al objeto, el art. 38, ambos de la mencionada Ley.

Según el art. 37.1, «El conflicto entre poderes del Estado es resuelto por el Tribunal Constitucional si surge entre órganos competentes para declarar definitivamente la voluntad del poder al que pertenecen y es relativo a la delimitación de la esfera de atribuciones determinada para los diversos poderes por normas constitucionales». Conforme al art. 38, «El Tribunal Constitucional resuelve el conflicto sometido a su examen declarando el poder al que corresponden las atribuciones discutidas $y$, si hubiera sido dictado un acto viciado de incompetencia, lo anula».

Pero el texto legal, al no mencionar exhaustiva y expresamente a los sujetos legitimados, se prestaba a diversas interpretaciones. La doctrina (seguida por la jurisprudencia) intentará adaptar la institución al pluralismo político y social reconocido en el propio texto constitucional. Ello exigía, por un lado, replantear, para ampliarlo, el círculo de sujetos legitimados y, en concreto, intentar la protección de las minorias parlamentarias y diputados, posibilitar los conflictos internos a las propias Cámaras; por otro lado, extender el objeto del conflicto más allá de la noción de vindicatio potestatis.

\section{B.2) Los sujetos legitimados}

En cuanto a la primera cuestión aludida (ampliación del círculo de sujetos legitimados), la doctrina y la jurisprudencia han revisado amplia-

24 Sobre los conflictos en Italia, entre nosotros, vid. F. J. GARCla RoCA, op. cit.; A. J. Porras Nadales, op. cit.; P. J. Tenorio Sánchez: "Los conflictos de atribuciones entre poderes del Estado en Italia", en RFDUC, n. ${ }^{\circ} 73$, Madrid 1988, págs. 377 y ss., y bibliografia alli citada. 
mente la tripartición clásica, reconociendo como partes en conflicto a la Presidencia de la República, a cada una de las Cámaras, al propio Tribunal Constitucional, al Tribunal de Cuentas, a todos los órganos jurisdiccionales, al Presidente del Consejo de Ministros (previa deliberación de éste y admitiendo la actuación, por delegación, de un Ministro).

No obstante, el intento de ampliar el círculo de sujetos legitimados encuentra un firme límite en el tenor literal del art. 37 citado, que por un lado obliga a multiplicar el número de «poderes» (si se quiere ampliar el de sujetos legitimados) y por otro, impide configurar conflictos internos a un poder. Ello, y la necesidad de mantener la distinción entre la esfera de los derechos fundamentales y la de la organización de los poderes, ha conducido a que incluso en las versiones doctrinales más abiertas - $M$. MAZZIOTTI- ${ }^{25}$ se haya tenido que negar la legitimación de los partidos políticos, de los grupos parlamentarios - como tales-y de los miembros del Parlamento individualmente considerados. Estos sujetos, efectivamente, no pueden ser considerados poderes del Estado (ni órganos que manifiesten definitivamente la voluntad de los mismos), ni siquiera considerando «poder del Estado" a cualquier sujeto cuya posición le permita detener o determinar decisivamente la formación de la voluntad del Estado. Se salvan, dentro de las Cámaras, las Comisiones de Investigación (cuya legitimación ha sido reconocida por el Tribunal Constitucional italiano) ${ }^{26} \mathrm{y}$, según la construcción de M. MAZZIOTTI ${ }^{27}$, en ciertos casos, las minorías. Éstas, en todos los supuestos en que la Constitución exige mayorias reforzadas pueden «detener» a un poder del Estado-Persona y, por tanto, pueden ser contempladas como «poder del Estado" ${ }^{28}$. No existen, sin embargo, precedentes jurisprudenciales al respecto.

En suma, la posibilidad de reconocer legitimación para ser parte a los protagonistas parlamentarios de la vida política (mayoria y oposición) está virtualmente descartada por la doctrina ( $y$ no existe jurisprudencia en tal sentido).

Por lo que se refiere a sujetos externos al Estado-Persona, tan sólo los Comités promotores de referendum han visto reconocida su legitima-

25 Op. cit., vol. l, págs. 383 y ss.

Sentencia T.C.I. n. $231 / 75$ (Giur. Cost., 1975, págs. 2197 y ss.).

${ }_{27}$ Op. cit., vol. I, págs. 258 y ss., y señala que en la doctrina (y parece que en la jurisprudencia) alemana se especifica que las minorias pueden actuar ante el Tribunal Constitucional para hacer valer los derechos que les atribuye la Constitución.

20 Aceptar semejante posibilidad plantea el problema de la identificación (pensemos en la posible votación secreta) de sus componentes, asl como el de su organización. M. MAZZIOTTI entiende que las minorlas se constituyen en el acto mismo en que manifiestan voluntad de hacer valer sus derechos y subsisten mientras mantienen su intención de hacerlos valer (pág. 262). Si la minoría no se constituye para ejercer un derecho suyo, no tiene relevancia politica. Reconoce que, para actuar, deben constituirse como grupos organizados. Si la minoría coincide con un grupo parlamentario, la organización del mismo podrla actuar en via de conflicto alo que no excluye que puedan constituirse organizaciones ad hoc, en el caso en que no exista una correspondencia entre minorias y grupos..." (pág. 263). 
ción. Y aun ello no parece tener grandes repercusiones, pues el Tribunal Constitucional se ha negado a examinar, en cuanto al fondo, las resoluciones del órgano de la Corte de Casación que resuelve sobre la procedencia del Referendum («Ufficcio Centrale per i Referendum presso la Corte de Casazzione").

\section{B.3) El objeto del conflicto}

En lo que concierne al objeto del conflicto, el Tribunal Constitucional italiano ha desbordado ampliamente los límites de la vindicatio potestatis, comprendiendo los supuestos de ejercicio de la propia competencia con menoscabo para otro poder (en su posición o en sus atribuciones constitucionales).

Más concretamente, se consideran supuestos de uso ilegítimo de un poder: a) los casos en que el poder es ejercitado bien con un objeto que no le es propio, bien faltando las condiciones y presupuestos de su ejercicio; b) los casos de violación de las normas sobre la forma y el procedimiento (en particular omisión de consultas y dictámenes); es dudosa la inclusión de los supuestos en que se alegan vicios lógicos en el proceso de formación de la voluntad del que el acto es resultado en el caso concreto (erróneas apreciaciones y valoraciones, de hecho o de derecho).

En cuanto al perjuicio irrogado al otro poder, puede consistir en una intromisión en la esfera de competencia reservada al recurrente en todo o en parte, en un impedimento para ejercer las propias atribuciones o en un obstáculo para la eficacia de sus actos; en la perturbación, en alguna manera, de su independencia como órgano del Estado.

No nos detendremos, a los efectos de esta exposición, en otros aspectos. Señalaremos tan sólo que el resultado perseguido con la actualización del instituto no ha sido alcanzado ${ }^{29}$, sino que esta competencia del Tribunal Constitucional, aun siendo marginal, se ha desbocado debido a la concepción del Poder Judicial como "poder difuso", superponiendose a los conflictos entre Administración y Justicia. En efecto, de $\mathbf{4 0}$ decisiones dictadas por el Tribunal Constitucional italiano en el ejercicio de esta competencia hasta mediado el año 1986, en 33 estaba implicado algún órgano judicial. Y tan sólo cinco conflictos habian llegado a tener una sentencia sobre el fondo.

2s Vid., por ejemplo, A. Pizzonusso: "La Magistratura come parte dei conflitti di attribuzioni", en Corte Costituzionale e sviluppo della forma di Governo in Italia, dirigido por $P$. Barile, Imola 1982, págs. 224-225, que concluye con la necesidad de “repensar la institución». 


\section{C) Conclusiones}

Este breve recorrido por los ordenamientos alemán e italiano nos permite las siguientes conclusiones sobre esta competencia de los respectivos Tribunales Constitucionales que venimos considerando como posible mecanismo de garantia de la posición de los sujetos interesados en el control o, si se prefiere, como vía para potenciar simplemente las posibilidades de control.

En primer lugar ha de reconocerse que, estadísticamente, esta competencia de los Tribunales Constitucionales ha tenido un desarrollo pobre.

En segundo lugar, en ambos paises existe, no obstante, el intento de adecuarla a las modernas interpretaciones del principio de división del poder que ofrecen las Constituciones actuales.

En tercer lugar, la regulación más idónea al intento es la alemana, aun cuando haya tenido dificultades para integrar a los poderes externos al Estado-Persona.

En cuarto lugar, resulta obvia la tendencia a la expansión de la institución, ampliando el círculo de sujetos legitimados y superando la vindicatio potestatis como objeto del conflicto o de la controversia.

Por último, parece que se confirma como via técnicamente apropiada para garantizar las atribuciones constitucionales a que venimos refiriéndonos.

\section{LA CUESTIÓN EN EL ORDENAMIENTO ESPAÑOL}

\section{A) Observaciones generales}

Ha de observarse, ante todo, que en nuestro ordenamiento las minorias tienen una importante facultad que no tienen, por ejemplo, en Italia ${ }^{30}$ : la legitimación para interponer recurso de inconstitucionalidad que

so Si, en cambio, en la República Federal Alemana, pero de manera más restringida: un tercio de los miembros del Bundestag pueden instar el control abstracto de constitucionalidad de las leyes: art. 76 LTCF (T. RITTERPACH, op. cit., pág. 35). O en Francia (reforma constitucional de 29 de octubre de 1974), donde 60 diputados o 60 senadores pueden instar el control preventivo de constitucionalidad de las leyes (art. 61 Constitución Francesa). 
nuestra Constitución otorga a 50 diputados y 50 senadores. Ello (y en general la amplia legitimación para interponer este recurso), acaso contrapese el carácter restrictivo con que los conflictos constitucionales, como veremos, vienen configurados. Incluso podría aceptarse que de tal modo tienen las minorias parlamentarias un medio de acción acaso más relevante de lo que suponen los conflictos en el Derecho extranjero a que hemos aludido.

Es más, ha de reconocerse que el supuesto control abstracto de normas, en la práctica, se acerca considerablemente a la Justicia Constitucional basada en el modelo conflictual. O dicho de otra manera, que los Tribunales Constitucionales, al ejercer la competencia de control abstracto de normas, emplean técnicas que en rigor corresponden a su competencia para resolver conflictos y que ello ensancha las posibilidades efectivas de judicialización del Derecho Constitucional.

Pero todo esto no cierra la cuestión planteada. El hecho de que globalmente existan más mecanismos de control (o de garantía de facultades de control), o el hecho de que, adulterando (o interpretando extensivamente, si se prefiere) competencias del Tribunal Constitucional puedan ampliarse los mecanismos de control, deja abierto el problema.

Porque de lo que se trata es de que las atribuciones que la Constitución formal (y otras normas que integran la organización constitucional) otorgan o reconocen a determinados sujetos, quedan garantizadas con rigor técnico. Rigor técnico que no es escrúpulo academicista, sino garantía de efectividad. Porque la multiplicación de garantias (o el solapamiento o superposición de las mismas, o de los procesos y competencias con que se corresponden) puede ser el medio más útil -0 si se quiere, el más torpe- de esterilizarlas. No se trata, pues, de multiplicar ciegamente las vias de acceso a la jurisdicción, ni de ensanchar arbitrariamente las existentes. «Que haya más mecanismos de control no significa que haya más control." ${ }^{31}$

B) Referencla a la regulación de los conflictos en nuestro ordenamiento

\section{B.1) Fuentes legales y sus caracteristicas}

Se impone, pues, aludir a la regulación de los conflictos constitucionales interorgánicos en nuestro ordenamiento ${ }^{32}$, para determinar si pueden cumplir esa función.

31 A. Torres del Moral, op. cit., págs. 237-238.

32 Vid. J. Almagro Nosete: Justicia Constitucional, Madrid 1980, págs. 275 y ss.; J. Ber- 
Como es sabido, la competencia para resolver conflictos constitucionales entre poderes no está prevista en la Constitución, sino que será la Ley Orgánica del Tribunal Constitucional (LOTC, n. 2/79, de 3 de octubre) la que, fundándose en el art. 161.1.d) del texto constitucional, la introduzca ${ }^{33}$ (art. 2.1.d). La LOTC regula en su Título IV "los conflictos constitucionales", incluyendo en dicho Título una disposición general (art. 59, en el Cap. I), la regulación de los conflictos entre Comunidades Autónomas (o entre éstas y el Estado) en el Capítulo II, y, en el Capítulo III, la de los "conflictos entre órganos constitucionales del Estado".

El planteamiento de la ley respecto de estos últimos resulta decididamente restrictivo, si se compara con el régimen existente en la República Federal Alemana o en Italia. Incluso prescindiendo de comparación alguna resulta previsiblemente muy poco utilizable ${ }^{34}$.

\section{B.2) Sujetos legitimados}

El círculo de sujetos legitimados resulta muy estrecho. El art. 59.3 LOTC atribuye competencia al Tribunal Constitucional para entender de los conflictos que se suscitan sobre las competencias o atribuciones que opongan «al Gobierno con el Congreso de los Diputados, el Senado o el Consejo General del Poder Judicial; o a cualquiera de estos órganos constitucionales entre si». Ofrece, pues, un elenco en principio exhaustivo.

La Ley Orgánica 2/82, de 12 de mayo, reguladora del Tribunal de Cuentas (L.O.T.Cu.) podría dar lugar a una sorprendente ampliación del círculo de sujetos legitimados, al disponer, en el art. 8.1, que «los conflictos

\footnotetext{
MEJO VERA: «La función resolutoria de los conflictos constitucionales negativos por parte del Tribunal Constitucional», en El Tribunal Constitucional, IEF, Madrid 1981, vol. III, págs. 575 y SS.; F. FeRnÁNDEZ SEGADO: La jurisdicción constitucional en España, Dykinson, Madrid 1984, págs. 163 y ss.; F. J. GaRcla RocA: El conflicto entre órganos constitucionales, Tecnos, Madrid 1987; J. GonzAlez Perez: Derecho Procesal Constitucional, Civitas, Madrid 1980, págs. 333-339 y 355 y ss.; J. J. González Rivas y L. Martin Retortillo: "Conflictos constitucionales de competencias y atribuciones", en El Tribunal Constitucional, cit., vol. III, págs. 211 y ss.; X. PIBERNAT: "Los conflictos constitucionales», en Rev. Jur. de Cat., n. ${ }^{\circ} 4,1982$, págs. 993 y ss.; A. J. PorRas Nadales, op. cit.; S. SÁNCHez GonzAlez: «La competencia del Tribunal Constitucional en materia de conflictos: una breve nota sobre una cuestión conflictiva”, en RDP UNED, $\mathrm{n} . .^{\circ} 16$, 1982-1983, págs. 193 y ss.; A. TORRES DEL MORAL, op. cit., vol. II, págs. 434 y ss.

33 Lo que se ha juzgado favorablemente: vid., por ej., F. RuBIo LLORENTE y M. ARAGÓN REYES: "La jurisdicción constitucional», en La Constitución Española de 1978. Estudio sistemático, dirigido por los profesores Alberto Predieri y E. García de Enterria, Civitas, Madrid, 2." ed., 1981, págs. 884-885.

${ }_{34}$ Asi se apuntó desde los primeros análisis: vid. L. Martín Retortillo, op. cit., concretamente págs. $228,236,249$, trabajo del que extraemos múltiples argumentos y jurisprudencia sobre el art. 42 LOTC, como se verá.
} 
que se susciten sobre las competencias o atribuciones del Tribunal de Cuentas serán resueltos por el Tribunal Constitucional».

Admitido que el Tribunal de Cuentas se añada al elenco de órganos legitimados del art. 59.3 LOTC — respecto de lo cual algún autor ha observado posible inconstitucionalidad- ${ }^{35}$, se plantea, en todo caso, una duda: si el Tribunal Constitucional ha de resolver o no los conflictos planteados frente al Tribunal de Cuentas cuando los que interpongan conflicto no sean los órganos del art. 59.3 LOTC; admitida la respuesta afirmativa, se plantearía la cuestión de si esos órganos tendrian que ser, al menos, órganos constitucionales.

Pero dejando al margen la problemática tan peculiar abierta asi por el art. 8.1 de la Ley Orgánica reguladora del Tribunal de Cuentas y limitándonos a la LOTC, cabe hacer las siguientes observaciones. En primer lugar, quedan excluidos órganos constitucionales no enumerados en el art. 59; Corona, Tribunal Constitucional, «Cortes Generales» (y Cámaras en sesión conjunta). Cabe plantearse la defensa de las atribuciones de estas últimas mediante la intervención de ambas Cámaras. Sin embargo, ello supondría una escisión entre el sujeto titular de la competencia y el sujeto con capacidad procesal que no parece muy viable sin previsiones normativas al respecto. De otro lado, el Tribunal Constitucional (Sentencia 45/ 86 ha considerado esta ausencia de legitimación de las Cortes para suscitar conflicto como una dificultad para considerar que la ley pueda ser objeto del conflicto entre órganos constitucionales.

En segundo lugar, los conflictos entre Gobierno, Congreso de los Diputados y Senado no son muy probables ${ }^{36}$. Hasta la fecha, los sistemas

${ }^{35}$ Ampliación discutible por el tenor del art. 162.2 de la Constitución (cir. X. PiBERnAT, op. cit., pág. 206); y por el carácter de lex consumens de la Ley Orgánica del Tribunal Constitucional, afirmado en su propio art. 1.1 (vid. L. MARTin Retortillo BAguer: Bajo el signo de la Constitución, IEAL, Madrid 1983, págs. 248-249); vid., sin embargo, J. M. RodrIGUEZ OLIVER: "Tribunal de Cuentas, Tribunal Supremo y Tribunal Constitucional", en El Tribunal de Cuentas en España, IEF, vol. II, Madrid 1982, pág. 1263.

La Sentencia del Tribunal Constitucional n. $.^{\circ} 45 / 86$, de 17 de abril, podría excluirlos en un obiter dictum: «El conflicto constitucional de atribuciones es un particular y especialísimo proceso que puede entablarse exclusivamente entre los organos constitucionales mencionados en el art. 59 de la LOTC..." (F.J. 1) (subrayado nuestro).

${ }^{36}$ La doctrina, sin dejar de indicar que en un sistema parlamentario los conflictos (son los que se sustancian ante la justicia) son impugnables entre Gobierno y Congreso, detecta algunos supuestos en que nuestro sistema ocupa algún espacio. Así, R. PUNSET: «El control jurisdiccional de la actividad de las asambleas parlamentarias y del Estatuto de sus miembros en el Derecho español», en RCG, n. 5 , págs. 35 y ss., sin dejar de hacer la observación indicada (pág. 67), se refiere a un número considerable de supuestos de posibles conflictos: 1) Gobierno frente a la Mesa del Congreso por la calificación de un proyecto como Ley Orgánica (pág. 53); 2) Gobierno frente al Congreso respecto de los requisitos establecidos por el art. 155 del Reglamento del Congreso en relación con la solicitud gubernamental de autorización parlamentaria del art. 94.1 CE, o frente al silencio del Congreso (págs. 53-54); 3) entre Senado y Congreso sobre el ejercicio senatorial de la iniciativa legislativa cuando el control de legalidad ejercitado en trámite de admisión por la Mesa del Congreso (arts. 31.1- 
electoral y de partidos existentes (y el electoral - Ley Orgánica 5/85 encuentra importantes condicionamientos constitucionales ${ }^{37}$ ) dan lugar, en el Senado, a la misma mayoría -incluso más sobrerrepresentada- dominante en el Congreso. Y por otro lado, en circunstancias normales obviamente esa misma mayoría será la presente en el Gobierno. Por supuesto que la moción de censura constructiva permite la existencia de un Gobierno que, políticamente, haya perdido la confianza del Congreso, pero los problemas que surgirian en tal caso seguramente tendrían que encontrar su cauce de resolución en el ámbito político, desbordando las posibilidades de cualquier mecanismo jurisdiccional.

En tercer lugar, y este aspecto tiene particular relevancia al objeto del presente trabajo, no parecen viables los conflictos suscitados por órganos internos o menores. Por un lado la composición de dichos órganos (vgr., Comisiones de las Cámaras) viene a reflejar la del Pleno, de modo que dificilmente podrían adoptar criterios distintos del mismo. Pero es que además, sólo el Pleno de los órganos legitimados puede apreciar que se ha producido invasión de competencias y plantear conflicto (arts. 59.3 y 73 LOTC). Cabria imaginar la posibilidad de que el Pleno tomara a su cargo la defensa de las competencias de un órgano menor (por ejemplo, podría plantearse el pleno la defensa de las atribuciones de una Comisión de investigación). Se trata de una hipótesis que, en ausencia de previsiones normativas al respecto, no parece viable, ya que supone una situación en la que el titular del interés (el organo menor) es distinto del sujeto procesal (el pleno, la Cámara) y podría conducir a situaciones absurdas (distinta posición del pleno y del órgano menor respecto de la conveniencia de continuar el conflicto frente a un tercero, por ejemplo). Pero sobre todo, con semejante regulación está claro que no resulta posible la defensa de la posición de las minorias parlamentarias, ni de los grupos parlamentarios, ni de los Diputados, frente a la Cámara (es decir, frente a la mayoría), en virtud del art. 59 LOTC; como tampoco cabe la defensa de los mismos frente a terceros, sin contar con el apoyo de la mayoría de la Cámara (es necesario el acuerdo del Pleno: art. 73 LOTC).

La problemática relativa al Consejo General del Poder Judicial merece atención separada. Es el órgano con el que más previsibles eran los

\footnotetext{
4. y $5 \mathrm{RG}$ ) se ejerciera abusivamente a juicio de la Cámara Alta (pág. 55); 4) entre Gobierno y Congreso, acerca del cumplimiento de lo preceptuado en los arts. 88 CE y $109 \mathrm{RC}$; 5) conflictos entre ambas Cámaras en torno al alcance contradictorio de las enmiendas en la tramitación de las leyes de armonización (150.3 CE, 168.3 RC) (pág. 60); 6) conflicto entre Gobierno y Senado por incumplir el Senado el plazo de dos meses de que dispone en el procedimiento legislativo ordinario para vetar o enmendar proyectos de ley (pág. 63); 7) conflictos entre Gobjerno y Cámaras por el ejercicio incorrecto de formas de control (pág. 67); 8) conflicto entre Gobierno y Cámaras o entre éstas entre si con motivo del control de la legislación delegada (pág. 68); 9) conflicto sobre el acto de "convalidación" de un Decreto-Ley (pág. 69).

${ }^{37}$ Vid. A. TORRES del Moral: Principios..., cit., vol. II, págs. 67 y ss.
} 
conflictos antes de la Ley Orgánica del Poder Judicial, y los hechos lo han demostrado. Con su actual composición, sólo la diferente duración de su mandato respecto del de las Cortes Generales y, el estatuto de sus miembros hacen imaginables los conflictos. Por otro lado, tras la sentencia del Tribunal Constitucional $n .^{\circ} 45 / 86$ ha quedado excluida la posibilidad de que actúe en defensa del Poder Judicial (lo cual, efectivamente, sin previsiones legales, no sólo era discutible que le correspondiera, sino dificilmente factible en muchos supuestos). En el ámbito de los conflictos constitucionales, el Consejo General del Poder Judicial puede defender tan sólo su posición y competencias (vgr., arts. 125, 127, 131, 133, 135 de la Ley Orgánica del Poder Judicial) mientras, para la defensa de las funciones jurisdiccionales queda el procedimiento de «conflictos de jurisdicción» ante el órgano mixto establecido por el art. 38 de la Ley últimamente mencionada ${ }^{38}$.

\section{B.3) Objeto del conflicto}

1. Por lo que se refiere a la configuración del objeto del conflicto, ha corrido análoga suerte a la del círculo de sujetos legitimados: a una regulación legal sumamente estrecha, que hace virtualmente inútil esta competencia del Tribunal Constitucional, se ha añadido una jurisprudencia constitucional cautelosa.

II. Comenzando con la regulación legal, efectivamente, en primer lugar, la LOTC no incluye los conflictos negativos (lo que supone una considerable laguna) ${ }^{39}$; piénsese en la posible negativa del Ministro de Justicia a refrendar un nombramiento propuesto por el Consejo General del Poder Judicial ${ }^{40}$; en segundo lugar, la dicción literal de la ley hace pensar en un planteamiento ceñido a la vindicatio potestatis: el art. 73.1 LOTC considera como presupuesto del conflicto que un órgano de los enumerados en el art. 59.3 «estime que otro de dichos órganos adopta decisiones asumiendo atribuciones que la Constitución o las Leyes Orgánicas confieren al primero"; y el art. 75.2 LOTC con respecto al contenido de la Sentencia dispone, ante todo, que ésta «determinará a qué órgano corresponden las atribuciones constitucionales controvertidas».

La experiencia italiana y la de la República Federal Alemana aconsejan considerar más bien como objeto del juicio la delimitación de los

3a Procedimiento regulado por la propia LOPJ y por la Ley Orgánica 2/1987, de 18 de mayo, de conflictos jurisdiccionales y las normas que sobre la materia deja vigente esta Ley.

39 Vid., no obstante, los argumentos de X. PIBERnAT, op. cit., pág. 208. Otros autores tienen una postura decididamente critica: L. MARTIN RETORTILLO, op. ult., cit., págs. 244 y ss.; J. Bermejo Vera, op. cit., págs. 599-600, propone que en ciertos casos, una omisión se entiende como indebida asunción de atribuciones y se resuelva como un conflicto positivo.

40 Apuntado por L. Martín Retortillo: Conflicto..., cit., pág. 246. 
«derechos» y de las “obligaciones» de los sujetos enfrentados ${ }^{41}$; es decir, entender como hipótesis de conflicto no sólo la vindicatio potestatis, sino cualquier menoscabo producido a otro órgano aun en el ejercicio de las propias competencias ${ }^{42}$.

III. Esta posibilidad no se excluye totalmente por parte de nuestro Tribunal Constitucional. En la repetida Sentencia 45/86, que en el caso que resuelve parece centrar la institución en la vindicatio potestatis, se dejan abiertos, no obstante, otras posibilidades en la medida en que se afirma que ésta constituye el «principal objeto» (F.J. 1).

Aún así, la postura del Tribunal no se corresponde con la adoptada en relación con algunos conflictos entre el Estado y las Comunidades Autónomas ${ }^{43}$.

En este ámbito, la Sentencia 32/83, de 28 de abril declaró ilegales determinados preceptos de un Real Decreto impugnado por el Gobierno Vasco, no porque el Estado fuera incompetente para regular la materia, sino por estimar que dicha materia debia haber sido regulada por Ley (con independencia, por tanto, de que la regulación de la materia no pudiere ser reivindicada por la Comunidad Autónoma). La Sentencia, es cierto, previene contra las generalizaciones. Afirma que el objeto del conflicto es la titularidad de la competencia controvertida e intenta delimitar el alcance de la excepción que introduce a dicha regla general: «en relación con determinadas materias de titularidad estatal, y de manera muy destacada en relación con la fijación de bases de una materia, un aspecto fundamental e indisociable del resto del debate es el de la concreción del órgano estatal llamado a ejercer esa competencia y asimismo el de la forma (norma con rango de ley o disposición reglamentaria) a través de la cual ha de ser ejercida la competencia en cuestión» (F.J. 1) ${ }^{44}$.

Si en el ámbito de los conflictos entre Estado y Comunidades Autónomas se admite este "ensanchamiento" del objeto, no parece que haya razones que justifiquen una orientación distinta con referencia a los conflictos entre poderes en el aspecto que nos ocupa.

41 Hemos visto que lo dice el proplo texto del art. 93.1.1 L.F. Bonn. Vid. F. SORRENTINo: "l Conflitti di attribuzione fra i poteri dello Stato", en Riv. Trim. di Dir. Pubbl., año XVII, 1967, págs. $716-720$.

42 Vid., p. ej., V. Crisafulli: "Cattivo uso del potere e conflitti di attribuzione», en Giur. Cost., 1980, I, págs. 220 y ss.; o F. Sorrentino, en Commentario delle Costituzione a cura di G. Branca, Zanichelli, Bologna-Roma 1981, sub. art. 137, pág. 474.

43 Vid., S. MuNoz Machado: Derecho Público de las Comunidades Autónomas, vol. II, Madrid 1984, págs. 323 y ss.; G. FERnÁNDEZ FARRERES: «El sistema de conflictos de competencias entre el Estado y las Comunidades Autónomas en la Jurisprudencia del Tribunal Constitucional', REDC, n. 12 , 1984, págs. 11 y ss.

44 Esta postura del Tribunal se confirmaría en la Sentencia $42 / 83$, de mayo (que resolvía el conflicto planteado por la Generalidad de Cataluña impugnando el mismo Real Decreto). 
Es cierto, no obstante, que los preceptos reguladores de unos y otros conflictos presentan algunas diferencias literales. En el ámbito de los primeros, los arts. 62 y 63, apdo. 1 (de la LOTC) señalan como supuesto que el recurrente estime que la disposición o resolución recurrida «no respete el orden de competencias», y el art. 66 (relativo a la Sentencia) preceptúa que el Tribunal anula la disposición, resolución o actos «viciados de incompetencia". En cambio, en relación con los conflictos interorgánicos, el art. 73.1 exige al órgano recurrente considerar como propia la competencia reclamada, y el art. 75 , apdo. 2 (contenido de la Sentencia) establece la nulidad de los actos ejecutados por «invasión de atribuciones».

Pero esas diferencias literales no parecen exigir un radical contraste entre ambas formas de conflictos ${ }^{45}$.

IV. Con todo, aceptado que el tenor literal de los preceptos no constituye un obstáculo para ello, lo que más inclina a una interpretación del objeto del conflicto de amplio contenido, que vaya más allá de la vindicatio potestatis, es la esterilidad a que queda condenada esta competencia en caso contrario, si tenemos en cuenta que la identificación de las funciones del Estado se Ileva a cabo, ante todo, con base en criterios jurídico-formales. Ello supone que el órgano que vulnera el orden de competencias queda a salvo (en un sistema de conflictos centrado o basado en la noción de vindicatio potestatis) con tal que el acto en cuestión revista la forma considerada paradigmática para el ejercicio de su función. Sólo disponiendo de un criterio material para la distinción de las funciones del Estado y de las atribuciones de los órganos constitucionales podría aceptarse la vindicatio potestatis como objeto del conflicto sin vaciar de contenido la competencia del Tribunal Constitucional consistente en resolverlos.

V. Este último orden de consideraciones resulta decisivo para no excluir la ley como posible objeto de conflicto ${ }^{46}$.

En el ámbito de los conflictos interterritoriales, nuestra doctrina parece excluir a la ley como posible objeto de los mismos ${ }^{47}$. Ahora bien, en

45 Para S. SAnchez Gonzalez, op. cit., págs. 199-200, acaso el propósito del legislador fue establecer una neta distinción entre ambos tipos de conflictos, pero no lo consiguió.

${ }_{46}$ En Italia es ésta también una cuestión polémica. Vid. F. J. Garcla Roca, op. cit., págs. 140-141 y pág. 203, y otros autores alli mencionados; Vid. M. Mazzıottı: / conflitti..., cit., vol. II, págs. 31 y ss.; G. Zagrebelsky, op. cit., pág. 201; F. SorRentino: I procedimento..., cit., págs. 464 y ss.; A. Pizzorusso, voz «Conflitto», cit., pfo. 16, pág. 387.

Vid. E. Alvarez Conde: «El Tribunal Constitucional y los conflictos entre las Comunidades Autónomas", en El Tribunal Constitucional, cit., vol. I, 1981, págs. 471 y ss.; F. MARTIN QUERALT: «Fiscalidad y conflictos constitucionales positivos de competencias entre Comunidades Autónomas", en op. ult. cit., vol. II, págs. 1657 y ss.; S. MUNOZZ MACHADO, op. cit., págs. 330 y ss. 
dicho ámbito existe una vía específica para impugnación de leyes: la que señala el art. 67 LOTC ${ }^{48}$.

En el ámbito de los conflictos entre órganos se argumenta ${ }^{49}$ que si existe una vía especifica (el recurso de inconstitucionalidad) la ley no puede impugnarse por otras vías, so pena de violar las normas que regulan la legitimación para interponer el recurso de inconstitucionalidad (art. 162.1.a) CE) ${ }^{50}$. Más concretamente la exclusión del Consejo General del Poder Judicial de la enumeración del art. 162.1.a) CE significaria, pues, que dicho órgano no puede pretender una declaración equivalente por medio del procedimiento de conflicto. A ello se añaden argumentos de orden literal: en primer lugar, el término «decisiones», del art. 73.1 LOTC excluye las leyes; en segundo lugar, se ha señalado que las leyes no son actos imputables a una Cámara, sino a las Cortes Generales, órgano al que no se recooce legitimación en el art. 59.3 LOTC.

En favor de la consideración de la ley como objeto de conflicto se aduce: en primer lugar, y concretamente frente a la última objeción indicada, que cabe suscitar conflicto contra los actos aprobatorios de cada Cámara durante el procedimiento legislativo; por otra parte, una interpretación precisamente inversa a la aludida anteriormente: sería precisamente porque el Consejo General del Poder Judicial no tiene legitimación para interponer recurso de inconstitucionalidad por lo que convendria considerar la ley como posible objeto de conflicto; pero sobre todo, la exclusión en términos absolutos de la ley (como objeto del conflicto) haría inatacables invasiones de las competencias de otros poderes siempre que se hicieran con forma de ley.

Se comprende, pues, la postura de nuestro Tribunal Constitucional. En la Sentencia 45/86 dirá que «plantear si en las relaciones entre órganos

40 «Si la competencia controvertida hubiera sido atribuida por una ley o norma con rango de ley, el conflicto de competencias se tramitará desde su inicio o, en su caso, desde que en defensa de la competencia ejercida se invocara la existencia de la norma legal habilitante, en la forma prevista para el recurso de inconstitucionalidad" (art. 67 LOTC).

49 Cfr. G. Peces Barba: El Tribunal Constitucional, cit. vol. III, pág. 2087. Argumentación del Letrado de las Cortes Generales en el caso de la Sentencia 45/86 (antecedentes, parágrafo 31).

so Resulta curioso constatar que algún autor itallano, con observaciones semejantes, llega a la conclusión opuesta. Asi, se argumenta (para el ordenamiento italiano) que dado que la ley se excluye como objeto de los conflictos intersubjetivos, porque en este ámbito los mismos sujetos tienen una via ad hoc para impugnar las leyes, es necesario considerarla (a la ley) posible objeto del conflicto entre poderes (porque en este ámbito los órganos legitimados no tienen otra vía de impugnación de las leyes) (ZaGrebelsky, op. loc. ult. cit.).

Esto muestra cómo este tipo de argumento, sin otros adicionales que justifiquen la conclusión final (que hay prohibición o laguna) no puede ser decisivo. Entre esos otros argumentos, podría señalarse que el elenco de sujetos legitimados para interponer el recurso de inconstitucionalidad es mucho más amplio en nuestro ordenamiento que en el italiano, lo que acaso podría apoyar soluciones distintas en uno y otro ordenamiento. Con todo, no existiendo limites literales que lo impidan, el argumento que nos parece decisivo es el indicado en el texto. 
constitucionales del Estado puede admitirse en abstracto la hipótesis de una invasión de atribuciones sub specie legis que, constitutiva de un vicio de la Ley por defecto de competencia, pudiera ser residenciado ante el Tribunal en el conflicto de atribuciones, supone un análisis excesivamente general, y que puede resultar en estos momentos no sólo prematuro, sino además innecesario». No obstante, la Sentencia alude a continuación a la dificultad de admitir tal posibilidad (en particular la procedencia de la Ley de las «Cortes Generales», órgano sin legitimación, según el art. 59.3) pero sin considerarla determinante de su decisión. Parece, pues, que la posibilidad de considerar la ley como objeto del conflicto entre órganos sigue abierta $^{51}$.

\section{B.4) La jurisprudencia constitucional}

I. Dada la regulación legal de la institución de los conflictos, no es de extrañar que, de momento, sólo se haya dictado una Sentencia del Tribunal Constitucional en esta materia: la ya citada Sentencia 45/86, de 17 de abril.

Se trata del conflicto planteado por el Consejo General del Poder Judicial contra los sucesivos actos de las Cámaras que aprobaron la LOPJ.

En particular, el Consejo ${ }^{52}$ solicitaba del Tribunal Constitucional: 1) la declaración de que la competencia para elegir a los doce miembros del CGPJ que han de ser elegidos «entre» jueces y magistrados, según el art. 122.3 CE, corresponde, conforme a dicho artículo, al conjunto de los jueces y magistados integrantes del Poder Judicial; 2) la declaración de que la competencia para dictar Reglamentos sobre el estatuto jurídico de los jueces y magistrados corresponde al Consejo con base en el art. 122.2 CE; 3) la declaración de nulidad de los actos sucesivos de las Cámaras con las cuales habia tenido lugar la aprobación de los artículos del proyecto de ley que, en el texto definitivo, serian los arts. 112.3 y Disposición adicional 1." parágrafo 2. ; el art. 113.3 de la LOPJ atribuye a cada Cámara la elección de los seis miembros del CGPJ que según la Constitución deben ser elegidos entre jueces y magistrados de todas las categorias en servicio activo; la disposición adicional 1.2 LOPJ establece que en el término de un año el Gobierno aprobará los reglamentos necesarios para el desarrollo de la LOPJ.

51 Por cierto que, caso de admitirse conflicto sobre una ley, se plantea la cuestión de si en el ámbito de estos conflictos ha de aplicarse o no el art. 67 LOTC.

${ }_{52}$ V. FaIRÉn GuILlÉn: Comentario a la Ley Orgánica del Poder Judicial de 1 de julio de 1985, Madrid 1986, págs. 134 y ss. 
Por tanto, el propio CGPJ planteaba su recurso sobre la base de la vindicatio potestatis, reivindicando para el conjunto del Poder Judicial la elección de los miembros que la Constitución no atribuía a las Cámaras y que la LOCGPJ ${ }^{53}$ había atribuido a los jueces y magistrados. $Y$ si el legislador quería establecer una competencia reglamentaria sobre el Estatuto de los jueces y magistrados, consideraba que ésta no podía corresponder al Gobierno, sino al órgano de gobierno del Poder Judicial.

Se planteaban asi, en otras, tres cuestiones: 1) si el CGPJ podia, por medio del procedimiento del conflicto, impugnar una ley (o los actos que integran el procedimiento legislativo); 2) la posición del CGPJ en el seno del Poder Judicial (es decir, si era órgano constitucional en sí mismo u órgano de representación con legitimación para plantear conflicto ante el Tribunal Constitucional) del Poder Judicial; si su posición como órgano de gobierno implicaba o no un poder reglamentario (en caso de que el legislador decidiera establecerlo); 3) la interpretación del art. $122 \mathrm{CE}$.

La Sentencia del Tribunal (la aludida Sentencia 45/86) si bien deja abierta la posibilidad (F.J. 1) de extender el objeto del conflicto más allá de la vindicatio potestatis ${ }^{54}$, así como la de considerar la ley objeto del conflicto (F.J. 3), a partir del F.J. 4 desenvuelve su argumentación decididamente entorno a una concepción del conflicto como institución centrada en la vindicatio potestatis: no puede ser invocada cualquier inconstitucionalidad o menoscabo, sino que es necesario que el órgano recurrente reivindique una competencia propia. Por tanto, el CGPJ no puede reclamar nada en nombre del Poder Judicial en su conjunto; en cuando al poder reglamentario, la disposición de la ley relativa al mismo no supone una lesión actual e inmediata de la función de gobierno de la Magistratura que corresponde al Consejo; podrá ocurrir si el Gobierno, al dictar las correspondientes normas, perjudica las competencias reconocidas al Consejo por la Constitución o la Ley Orgánica.

Por todo ello, el Tribunal Constitucional desestima los conflictos planteados $^{55}$.

II. Hasta aquí los conflictos constitucionales que, en sentido estricto, pueden ser considerados como tales. Ahora bien, la contemplación del problema que nos ocupa (el de la garantía de la función de control) en el ámbito de la jurisprudencia constitucional exige una referencia a lo que (empleando una noción de «conflicto constitucional de atribuciones» ex-

ss Ley Orgánica 1/1980, de 10 de enero, del Consejo General del Poder Judicial.

54 En la medida en que afirma que el conflicto de atribuciones tiene por «principal» objeto una vindicación de competencia.

${ }_{55}$ Como se sabe, la LOPJ fue también objeto de un recurso de inconstitucionalidad. La Sentencia correspondiente (108/1986, de 29 de julio) señaló la interpretación conforme a la Constitución de la disposición adicional primera de la LOPJ y desestimó el recurso en todo lo demás. 
traida del Derecho extranjero anteriormente aludido) podríamos denominar "conflictos planteados como recursos de amparo" o, más genéricamente, "conflictos encubiertos».

Ya hemos visto cómo en nuestro sistema las minorias parlamentarias (ciertas minorías) tienen un medio de actuación nada desdeñable en el recurso de inconstitucionalidad. Veamos ahora cómo el recurso de amparo puede venir a paliar las faltas de garantía a que conducen los términos restrictivos en que se configuran los conflictos en la LOTC. Dos dificultades se presentan para que el recurso de amparo cumpla semejante papel: la doctrina de la interna corporis acta; y el hecho de que el recurso de amparo proteja los "derechos fundamentales». Dificultades que no pueden contemplarse desarraigadas de las que puede plantear la concreta legislación en la materia: en particular, el art. 42 LOTC.

1. La Sentencia $16 / 84$, de 6 de febrero (aclarada por Auto del Pleno del 16 de febrero de 1984) resolvió dos impugnaciones de la resolución del Presidente del Parlamento de Navarra (de 25 de agosto de 1983) proponiendo al Rey la designación de Presidente del Gobierno de dicha Comunidad Autónoma: la impugnación del Gobierno (por el cauce del Título V de la LOTC) y el recurso de amparo de un miembro de la Cámara que, por ser el candidado del Partido que había obtenido mayor número de escaños en las elecciones (PSN-PSOE), consideraba debía haber sido el candidato propuesto al Rey (en aplicación del art. 29.3, in fine de la L.0. 13/1982, de 10 de agosto, de Reintegración y Amejoramiento del Régimen Foral de Navarra - LORARFNA-).

El asunto tuvo acceso al Tribunal (que anuló la propuesta de nombramiento) por la impugnación del Gobierno. Ni los grupos ni los partidos implicados hubieran encontrado cauce para hacer valer sus pretensiones. Y tampoco el que podriamos llamar "candidato expectante» ex-art. 29.3, de la L.O. 13/82, a quien se denegó el amparo solicitado. A este respecto, el Tribunal declaró (F.J. 10) que «al no haber sido pertinente la iniciación del procedimiento extraordinario del art. 29 in fine de la LORARFNA y art. 20.8 de la Ley Foral 23/83, no existió, en ningún momento, miembro alguno de la Cámara que hubiera podido ostentar el derecho a ser propuesto en virtud de dicho procedimiento, por lo que, consecuentemente, no puede hablarse de un derecho en este sentido protegible en amparo en favor del recurrente..., ni violación, por tanto, del art. 23.2 de la CE...".

Dos observaciones hemos de hacer. En primer lugar, si el amparo ha de proteger derechos fundamentales en ningún caso -entiéndase, tampoco en el caso de que hubiera sido pertinente la iniciación del procedimiento extraordinario del art. 29 in fine de la LORARFNA- hubiera sido admisible un recurso de amparo en este supuesto; no habría, en principio, derecho subjetivo público de los ciudadanos (como tales) a exigir el cumplimiento de normas constitucionales reguladoras del funcionamiento in- 
terno de los órganos constitucionales o de las relaciones entre ellos. La pretensión del "candidato expectante» hubiera tenido su cauce adecuado en un procedimiento de conflicto ${ }^{56}$.

En segundo lugar, ha de indicarse que aqui ya se percibe el cauce que nuestro Tribunal Constitucional encontrará para colmar la laguna de que venimos hablando; el art. 23.2 de la $C E{ }^{57}$.

2. Otro asunto en el que podría verse un conflicto encubierto seria el resuelto por el Auto de inadmisión de la Sala II del Tribunal Constitucional, Auto n. ${ }^{\circ} 123 / 84$, de 21 de marzo ${ }^{58}$. Un Senador impugnó por vía de amparo constitucional las normas supletorias sobre ordenación del debate del proyecto de Ley Orgánica reguladora del Derecho a la Educación (LODE) dictadas el 14 de febrero por el Presidente del Senado; el recurso se fundaba en la pretendida violación de los arts. 14 y 23, apdo. 2 de la Constitución.

Las normas impugnadas habian sido dictadas por la Presidencia del Senado, oida la Junta de Portavoces y con el acuerdo de la mayoría de la Mesa de la Comisión de Reglamento. La Presidencia mencionada justificaba en el preámbulo la oportunidad de las normas fundándose en la necesidad de cumplir el plazo previsto en el art. 90 de la Constitución; y en cuanto a sus facultades para dictarlas, invocaba alternativamente, $o$ bien sus facultades para la ordenación de los debates, o bien la facultad de interpretación del Reglamento y de suplencia de las lagunas (art. $37 \mathrm{del}$ Reglamento del Senado).

56 No queremos decir con ello que sea oportuno asignar al Tribunal Constitucional los posibles conflictos internos de todas las Comunidades Autónomas. Tan sólo indicar que existe de alguna manera una laguna en nuestro sistema de justicia constitucional, como por lo demás ha sido señalado en otras ocasiones. R. Punset.

57 Distinto es, a nuestro entender, dentro de las dificultades que plantea el art. 23.2 (por ser precisamente el punto de conexión de la esfera de la organización estatal uformalizada" con el electorado o pueblo) el caso resuelto por la Sentencia 28/1984, de 28 de febrero: unos parlamentarios impugnan en amparo el acuerdo de la Mesa del Parlamento de Navarra que los cesa como parlamentarios por haber dejado de pertenecer al partido por cuyas listas habian salido elegidos (en virtud del art. 11.7 de la Ley de elecciones locales, sobre el cual, por lo demás, existía una jurisprudencia constitucional: Sentencia 5/1983, de 4 de febrero, por ejemplo). Con un sistema de conflictos amplio, pertenecerian al ámbito de los mismos la discusión de ciertos "derechos" o atribuciones del parlamentario, es decir, del parlamentario Indiscutido. Cuando lo que se discute es la misma condición de parlamentario, si estamos ante un supuesto del 23.2 ante la discusión de un derecho fundamental, que se corresponde con la vía de amparo.

Iguaimente, los casos relativos al alcance del requisito del juramento exigido por los Reglamentos parlamentarios para adquirir la condición de parlamentario (Sentencias del T.C. 101/83, de 18 de noviembre, y 122/83 de 16 de diciembre, cuyos criterios se vendrian a confirmar en el art. 108.6 de L.O. Electoral $5 / 85$, de 18 de junio) son relativos al derecho fundamental de acceso a los cargos públicos (art. 23) y su via de resolución es el recurso de amparo.

so Vid., al respecto, 1. ToRRes MURo: «Actos internos de las Cámaras y recurso de amparo. Un comentario al auto del Tribunal Constitucional de 21 de marzo de 1984", en REDC, n. 12,1984 , págs. 153 y ss. 
La Sala inadmitió el recurso fundándose, en primer lugar, en que se pretendía una impugnación directa de normas, lo que no era posible según el tenor literal del art. 42 LOTC, que se refiere a «las decisiones o actos sin valor de ley emanados de las Cortes o de cualquiera de sus órganos".

Para el Tribunal, «...el simple tenor literal de este artículo representa ya el primer obstáculo infranqueable para la admisión del presente recurso, pues lo que en él se impugna es una norma y el citado precepto no habla de normas, ni de disposiciones, sino sólo de actos o de resoluciones, es decir, de decisiones que en la terminología habitual entre nosotros tienen contenido singular, no general».

En segundo lugar, la Sala argumentó basándose en la inmunidad de los interna corporis: «La norma impugnada es, en efecto, un acto interno de la Cámara, producido por la Presidencia de ésta y que tiene por finalidad la regulación de las relaciones que existen entre la Cámara y sus propios miembros. No es, por tanto, una norma que deba regular las relaciones de la Cámara con terceros vinculados con ella por relaciones contractuales o funcionariales, sino un acto puramente interno de un órgano constitucional. Característica propia de éstos es la independencia y el aseguramiento de ésta obliga a entender que, si bien sus decisiones, como sujetas que están a la Constitución y a las Leyes, no están exentas del control jurisdiccional, sólo quedan sujetas a este control cuando afectan a las relaciones externas del órgano o se concretan en la redacción de normas objetivas y generales susceptibles de ser objeto del control de inconstitucionalidad, pero ello sólo, naturalmente, a través de las vías que para ello se ofrecen".

Intentando precisar la jurisprudencia que se puede derivar de este Auto parece que debe ponerse el acento en la exención de control de los interna corporis ${ }^{59}$. En efecto, si se planteara el mismo supuesto, con formulación distinta, parece que ese sería el obstáculo decisivo. Queremos decir con ello que, siguiendo la argumentación del Auto, si se hubiera planteado por vía de amparo la impugnación de actos de ejecución de normas consideradas inconstitucionales, el Tribunal no hubiera concedido el amparo si se hubiera planteado la impropiamente llamada «autocuestión de inconstitucionalidad" ${ }^{60}$ del art. 55, apdo. 2 LOTC por considerar que se hallaba ante actos internos.

59 Vid. L. Martin Retortillo: «El control por el Tribunal Constitucional...", cit., págs. 112 y ss., y en particular $n .^{\circ} 29$ quien entiende que la alusión a la doctrina de los actos internos, por parte del Tribunal en un caso como éste es «un mero recurso dialéctico del que no hay que sacar mayores consecuencias". En todo caso, su análisis no es incompatible con otro que se ciña a las afirmaciones textuales del Auto.

60 Impropiamente, porque lo previsto en el art. 55.2 no es la resolución del asunto abriendo un incidente. Así, R. PUNSET BLANCO: «El control jurisdiccional de la actividad de las Asambleas Parlamentarias y del Estatuto de sus miembros en el Derecho español", en RCG, n. ${ }^{\circ}$, págs. 40-41. 
Pues bien, prescindiendo del fondo del asunto, interesa hacer las siguientes observaciones. En primer lugar, si la doctrina de los interna corporis $^{61}$ significa la exención de control jurisdiccional de los actos internos de las Cámaras, o dicho de otro modo, la inadmisión de cualquier impugnación de los mismos, dicha doctrina ha de ser reemplazada por una ponderación, con motivo del conocimiento del fondo del asunto, de la necesaria independencia de los órganos constitucionales. Dicha independencia debe ser contrapesada por la necesidad de proteger a las minorías parlamentarias y a los miembros de las Cámaras. Por lo demás, que dicha teoría hoy no puede admitirse en términos absolutos es algo que se desprende del propio art. 42 LOTC. En segundo lugar, la vía adecuada para resolver conflictos como el presente -y esto, obviamente, es una afirmación de lege ferenda- debiera ser la del conflicto. Las atribuciones de los parlamentarios no son, en rigor, derechos fundamentales, por más que se les aplique protección semejante, interpretando extensivamente el artículo 23.2 CE.

3. En el siguiente caso ${ }^{62}$ a que vamos a referirnos no hubo conflicto interno a la Cámara. Se trata del de la Sentencia del Tribunal Constitucional 90/1985, de 22 de julio ${ }^{63}$. Presentada querella contra un escritor, luego elegido Senador, la Sala II del Tribunal Supremo solicitó el correspondiente suplicatorio, que fue denegado. El querellante recurre en amparo dicha

-1 Vid. I. Torres Muro: Actos internos de las Cámaras..., cit. págs, 160 y ss., y bibliografia alli citada.

62 Existen otras resoluciones del Tribunal que, aun refiriéndose a actos internos (en sentido amplio) de las Cámaras y a la aplicación del art. 42 LOTC, no se refieren a uconflictos constitucionales encubiertos». Serlan, por ejemplo, los Autos n. ${ }^{\circ} 241 / 84$, de 11 de abril (selección de una plaza de funcionario para las Cortes de Castilla y León), el de 2 de mayo de 1984 (selección para una plaza de auditor de la Cámara de Comptos dependiente del Parlamento de Navarra), el de 26 de septiembre de 1984 (convocatoria de un concurso para cubrir plaza de Letrado, Parlamento de Baleares, que acabó por desistimiento), el del Auto n. ${ }^{\circ} 296$ / 85, de 8 de mayo. En este último se declara inadmisible (ex-art. 50.2.b) LOTC) el recurso de amparo planteado por unos funcionarios de carrera de la Diputación Foral de Navarra contra el Acuerdo de la Mesa del Parlamento de Navarra de 15 de octubre de 1984 por el que se aprueba la modificación de determinados artículos del Estatuto de Régimen y Gobierno Interior del Parlamento de Navarra (normas que equiparaban funcionarios "adscritos" y funcionarios de carrera) y contra el acuerdo del mismo órgano de 20 de noviembre de 1984 desestimatorio del recurso interpuesto contra el anteriormente mencionado. EI TC argumentó que el recurso era inadmisible tanto si se trataba de impugnar un acto (pues en tal caso éste no era firme) como si se entendía como una impugnación directa de una norma, pues en tal caso no estaría comprendida la hipótesis del art. 42 de la LOTC, pues el amparo previsto en esta disposición es contra "decisiones o actos sin valor de ley", no pudiendo interponerse un recurso directo contra los actos con valor de ley.

Se trata de enfrentamientos entre funcionarios y órganos, que están fuera del marco del presente trabajo. Dicho en los términos del Auto de 21 de marzo de 1983 no se trata de actos internos, sino de relaciones con terceros vinculados a la Cámara por relaciones contractuales of funcionariales.

* También en relación con este caso, Sentencia 92/85, de 24 de julio, relativa a dos Autos del Tribunal Supremo recaidas sobre el mismo asunto. 
denegación, así como los Autos subsiguientes del Tribunal Supremo. El Tribunal Constitucional otorgará el amparo basándose entre otras razones, en que se trataba de un acto de relevancia juridica externa (F.J. 2) y en la vulneración de derechos fundamentales.

En este caso, tal y como se planteb, no puede hablarse de conflicto, ni siquiera encubierto. Pero supuestos de hecho semejantes podrian sustanciarse (o pretender sustanciarse) por tal vía. Con un sistema de conflictos más amplio, podría, por ejemplo, haberse planteado uno entre Tribunal Supremo y Cámara Parlamentaria.

4. Otro supuesto "conflicto encubierto" podría encontrarse en el Auto de 26 de julio de 1984: seis parlamentarios canarios, fundándose en el art. 23.1, interponen recurso de amparo contra determinados actos de órganos del Parlamento Canario (Presidente, Junta de Portavoces) en relación con la tramitación del Proyecto de Ley de Presupuestos Generales de la Comunidad Autónoma. Todas las partes consintieron en el desistimiento. En el Auto, el Tribunal Constitucional declara terminado el procedimiento por desistimiento y condena al pago de las cuotas, lo que justifica, entre otras razones, en que "las infracciones denunciadas por los demandantes o bien carecen de la mínima entidad, o bien sencillamente no se han producido...".

5. El Auto n. 12/1986, de 15 de enero, es relativo al recurso de amparo presentado por un Diputado contra la resolución de la Presidencia del Congreso publicada en el BOCG, de 24 de abril de 1985, sobre «procedimiento para ejecutar sentencia del Tribunal Constitucional» y contra posteriores actos adoptados en virtud de la misma. El recurrente sostenía que determinadas limitaciones de los derechos de los Diputados (en particular, el de presentar enmiendas) en que incurría dicha resolución (y los actos que la habian aplicado) vulneraban el art. 23, apdo. 1 de la Constitución.

El Tribunal inadmitió la demanda, argumentando que «no toda infracción de los Reglamentos de las Cámaras... constituyen otras tantas violaciones de derechos fundamentales", reitera la inmunidad de los actos internos, invocando expresamente el Auto de 21 de marzo de 1984, y añade que "...sólo en cuanto lesionen un derecho fundamental reconocido en la Constitución y no por infracción pura y simple de un precepto del Reglamento de la Cámara, son recurribles en amparo tales actos internos, en virtud de lo dispuesto en el art. 42 de la LOTC» (F.J. 2). Por lo demás, añade, «no se colige de qué manera han podido infringir los actos impugnados el derecho de participación que a los ciudadanos $-y$ no a sus representantes- reconoce el invocado art. 23.1 de la CE".

6. La Sentencia $118 / 1988$, de 20 de junio, resuelve el recurso de amparo promovido por 67 diputados contra la Resolución de la Presìdencia 
del Congreso de los Diputados de 18 de diciembre de 1986, sobre acceso a materias clasificadas ${ }^{64}$. Invocando el art. 20.1.d) CE, el derecho peculiar a la información que tienen los diputados (y mencionando el art. $23 \mathrm{CE}$ ), el art. $109 \mathrm{CE}$ y otros preceptos legales, solicitaban que se declarara la nulidad de la Resolución impugnada. En favor de la desestimación del recurso, se habla alegado, entre otros argumentos, que el acto impugnado era un acto puramente interno, y que se trataba de una norma no impugnable por el art. 42 LOTC.

El Tribunal examina la primera alegación aludida (en el F.J. 2) ofreciendo una sintesis de lo que estima ser la jurisprudencia constitucional al respecto ${ }^{65}$ : existen actos puramente internos exentos de control por vía de recurso del art. 42 LOTC (cita diversos Autos al respecto); pero esta regla no excluye el examen de los actos que hayan vulnerado los derechos fundamentales y libertades públicas de la Sección 1. ${ }^{a}$ del Capítulo Segundo del Título I de la CE (cita la STC 90/85 y los Autos de 11 de marzo de 1987 $y$ el 12/1986, de 15 de enero).

Esta interpretación de la jurisprudencia significa que la simple invocación de un derecho de la mencionada Sección basta para soslayar la aplicación de la doctrina de los interna corporis. El propio Tribunal viene a reconocerlo. «... En el presente recurso los solicitantes de amparo han sostenido que la resolución impugnada ha lesionado derechos fundamentales propios susceptibles de amparo constitucional. Por ello no cabria invocar el carácter interno del acto para impedir su examen en esta vía de amparo..." ${ }^{66}$.

La segunda cuestión importante que desarrolla el Tribunal (FF.JJ. $n$. 3 y 4) es la de la naturaleza de ciertas resoluciones «normativas» de la Presidencia del Congreso. Para el Tribunal, una interpretación conjunta de los arts. 27 y 42 LOTC y del 161.1.a) CE lleva a la conclusión de que, precisamente por excluir el art. 42 los actos con valor de ley, ciertas manifes-

64 BOCG-CD, de 19 de diciembre de $1986\left(n^{\circ} 4\right)$.

6s «En una serie de Autos como los de 21 de marzo de 1983, 8 de mayo de 1985, 15 de enero de 1986, 12 de marzo de 1986, 11 de marzo de 1987 y 27 de mayo de 1987, este Tribunal ha sostenido que quedan excluidos de verificación en el recurso de amparo del citado art. 42 los actos que merecen la calificación de "actos internos" de la Cámara... Pero ello no excluye, sin embargo, la posibilidad de examinar si aquellos actos han vulnerado en concreto los derechos fundamentales y libertades públicas incluidos en la Sección 1." del Capítulo Segundo del Título I de la Constitución... para cuya protección queda abierta la vía de recurso de amparo (STC 90/1985, de 22 de julio). La doctrina de los interna corporis acta solo es aplicable en la medida en que no existe lesión de tales derechos y libertades...» «Quiere con ello decirse que, sólo en cuanto lesionan un derecho fundamental reconocido en la Constitución y no por infracción pura y simple de un precepto de la Cámara, son recurribles en amparo tales actos.... (ATC'de 11 de marzo de 1987). En cuanto un acto parlamentario afecte a un derecho o libertad susceptible de amparo constitucional, sale o trasciende de la esfera irrevisable propia de los interna corporis acta y corresponde a este Tribunal el examen, pero sólo ello, de la virtual lesión de tales derechos o libertades (ATC 12/1986, de 15 de enero).»

B Bajo la apariencia de una jurisprudencia constante, se está produciendo una importante evolución en cuanto a la doctrina de los interna corporis. Volveremos sobre ello. 
taciones normativas procedentes de órganos parlamentarios pueden ser reconducidos al art. 27.2 LOTC, admitiéndose el recurso de inconstitucionalidad frente a ellos. Se invocan los Autos del TC 183/84 (Resolución del Presidente del Senado) y el 244/86, de 12 de marzo (Resolución de la Presidencia de la Asamblea de Madrid). Esta solución permite un control de tales normas que comprenda cualquier inconstitucionalidad de las mismas (no se controlan sólo por violación de los derechos fundamentales) y no excluye el recurso de amparo, indirecto, frente a ellas.

Como la Resolución impugnada no es una «decisión o acto sin valor de ley» susceptible de conocimiento por la vía del recurso de amparo del art. 42 de LOTC, el TC desestima el recurso de amparo ${ }^{67}$.

7. La Sentencia TC $161 / 1988$, de 20 de septiembre, resolvió el recurso de amparo promovido por cuatro diputados de las Cortes de CastillaLa Mancha contra un Acuerdo de la Mesa de las Cortes de dicha Comunidad Autónoma en virtud del cual no se admitió a trámite una solicitud que recababa determinada documentación al Consejo de Gobierno de la Junta (hubo un posterior acuerdo de la Mesa que desestimó el recurso contra su anterior Acuerdo).

Los recurrentes invocaban el art. 29.1 CE (en relación con el art. 12.2 del Reglamento de las Cortes de Castilla-La Mancha), el 9.3, el 23.1, el 103, el 105.b) y el 11.1 CE.

El Tribunal reitera, mencionándola, la doctrina de los interna corporis de la Sentencia $118 / 88^{68}$ para afirmar que «... procede... desestimar la causa de inadmisibilidad alegada por el Letrado de las Cortes de CastillaLa Mancha, puesto que los demandantes denuncian que el acto parlamentario recurrido les ha lesionado derechos fundamentales susceptibles de amparo...» (F.J. 3).

El derecho que puede verse afectado (FF.JJ. 4, 5, 6) por el acto impugnado es el del art. 23.2 CE que no ha sido invocado, pero el Tribunal entiende que «debe atender los recursos de amparo siempre que, por encima de posibles equivocos en el señalamiento de las normas constitucionales, el derecho fundamental presuntamente violado se identifique con precisión» y porque los recurrentes sí habian invocado el 23.1 y «la norma

${ }^{67}$ El Magistrado F. Rubio Llorente, en voto particular, se manifiesta de acuerdo en atribuir rango de Ley a la Resolución impugnada. Pero matiza que son recurribles en amparo las normas de tal rango que no necesitan intermediación de acto alguno de aplicación; y que la decisión de inadmisión debia haberse acompañado de otra que dejara en suspenso el plazo que los recurrentes tenian para interponer contra la norma impugnada recurso de inconstitucionalidad.

${ }_{6 \theta}$ Indica como excepción al carácter irrevisable el supuesto en que se imputa al acto haber ocasionado concreta vulneración de los derechos fundamentales y libertades politicas reconocidas en el art. 14 y en la Sección primera del Capitulo II del Título I de la Constitución... Por lo demás, veremos, no es tan rígida en la exigencia de invocación del 23.2 (a diferencia del Auto 12/86). 
contenida en el art. 23.1 resulta inseparable de la del 23.2 cuando se trata, como aqui ocurre, de una petición de amparo deducida por representantes parlamentarios en defensa del ejercicio de sus funciones (Sentencias TC 10/1983, de 21 de febrero y 32/1985, de 6 de marzo)" (F.J. 6).

El Tribunal entiende que el art. $12.2^{69}$ del Reglamento de las Cortes de Castilla-La Mancha crea en favor de los parlamentarios un derecho individual a recabar información a la Administración Regional, derecho que se integra en el status propio del cargo de diputado y se inserta y forma parte del derecho fundamental que garantiza el art. 23.2 de la Constitución. No se trata de una actividad de propuesta ${ }^{70}$ y las facultades de la Mesa al respecto no suponen un control de oportunidad (F.J. 8).

Como quiera que la motivación del Acuerdo de la Mesa se apoyaba en cuestiones de oportunidad, el Tribunal concede el amparo.

III. Considerando conjuntamente estos «conflictos encubiertos"parece que con una apariencia de jurisprudencia constante, se han producido considerables cambios: a) en primer momento (Auto de 21 de marzo de 1983, Auto de 8 de mayo de 1985) el Tribunal sostuvo que quedaban excluidos de verificación en el recurso de amparo del art. 42 LOTC los actos internos de la Cámara; b) en la Sentencia 90/85, de 22 de julio (hasta donde hemos alcanzado a ver), se introduce una excepción: en la incidencia de esta Sentencia hay que distinguir dos cuestiones distintas: la que real y estrictamente tenía y la que de hecho, conjugada con posteriores Resoluciones del Tribunal, ha tenido. En cuanto a su incidencia estricta, esta Sentencia deja en cierto sentido intacta una determinada concepción de la doctrina de los interna corporis. Es cierto que acaba con uno de los significados o funciones que habia tenido. Pero la teoria podia permanecer en tanto en cuanto lo que hace anular un acuerdo del Pleno del Senado (denegando un suplicatorio) es reconocer que un determinado tipo de actos tienen tras-

69 El art. 12.2 del Reglamento de las Cortes de Castilla-La Mancha dispone que «Para el mejor cumplimiento de sus funciones, los Diputados podrán recabar los datos, informes y documentos que obren en poder de la Administración Regional», añadiendose en el párrafo siguiente del mismo precepto que cla solicitud se dirigira, en todo caso, al Presidente de las Cortes y, admitida ésta, le dará traslado a la Administración requerida para que facilite la documentación solicitada en el plazo de treinta dias o manifieste en el mismo las razones fundadas en Derecho que to impidan", según el n. 4 de este art. 12 , en el supuesto de que los Diputados no estén de acuerdo con las decisiones tomadas por la Mesa, podrán recurrir ante la misma, de acuerdo con el procedimiento establecido en el art. 30.2, del Reglamento.

70 $\propto \mathrm{A}$ diferencia de lo que dispone nuestro Derecho respecto de la participación de los parlamentarios en el ejercicio de otras atribuciones de las Cámaras (como la de iniciar el procedimiento legislativo: Auto 659/1987, de 27 de mayo), la facultad que aquí consideramos no se realiza mediante meros actos de propuesta a traves de los que un parlamentario o grupo de ellos, insta a la Cámara para que haga suya una determinada iniciativa, pues no es el órgano parlamentario el que recaba la información, sino alguno o algunos de sus miembros, a título individual, por más que la decisión, en sí perfecta, quede condicionada a su "admisión" por la Mesa y a su tramitación ad extra a través del Presidente de la Cámara" (F.J. 7). 
cendencia externa. En este caso, habia efectivamente un derecho fundamental vulnerado, era un derecho de un tercero ajeno a la Cámara.

Pero al establecer como excepción a la doctrina de los interna corporis con carácter general la alegación de la vulneración de un derecho fundamental, sí parece quebrarse el último vestigio de tal doctrina, o al menos, se ponen las bases para que eso suceda. Esta doctrina se va a proyectar hacia los auténticos «actos internos», por la misma vía que esto podía tener lugar: a través de una interpretación del art. 23.2 CE que considera ciertas atribuciones constitucionales o reglamentarias de los parlamentarios incluidas en dicho precepto. Porque en rigor, no se alcanza cómo otro derecho fundamental de los parlamentarios puede ser vulnerado por un acto interno de la Cámara. Si los derechos fundamentales dibujan el ámbito de la Sociedad distinto del ámbito del Estado (salvo el derecho de acceso a los cargos públicos, que conecta a ambas esferas), entonces, cuando algún ciudadano defienda un derecho fundamental que no sea el de acceso a los cargos públicos se está moviendo en una relación juridica externa, y no en una relación jurídica interna a la Cámara. Los mismos diputados, en cuanto defienden derechos fundamentales (distintos del reconocido en el $23.2 \mathrm{CE}$ ), lo hacen como ciudadanos, en el marco de una relación jurídica que escapa al ámbito de la doctrina de los interna corporis.

Pues bien, la consagración de la doctrina de la Sentencia 90/85 fuera de su contexto, va a suponer un cambio en la materia. Todavía algunas resoluciones hacen una repetición de la doctrina sin consecuencias prácticas y teóricas nuevas: el Auto n. 12/86, F.J. 2, por ejemplo: «...sólo en cuanto lesionen un derecho fundamental reconocido en la Constitución y no por infracción pura y simple de un precepto del Reglamento de la Cámara, son recurribles en amparo tales actos internos, en virtud de lo dispuesto en el art. 42 LOTC».

Sin pretender innovar, sino tan sólo recoger jurisprudencia anterior, las Sentencias $118 / 1988$ y $161 / 1988$ conllevan importantes novedades. En ambos casos son ya parlamentarios como tales los que recurren actos de la Cámara y por tanto actos internos en sentido estricto. La primera de ellas afirma que dado que los recurrentes han sostenido que la resolución impugnada ha lesionado derechos fundamentales propios susceptibles de amparo constitucional, no cabe invocar el carácter interno de un acto para impedir su examen por vía de amparo. La segunda viene a apuntalar esta idea indicando el precepto que habría de invocarse, el art. 23.2 CE aun cuando no habia sido invocado por los recurrentes) porque ceste Tribunal debe atender los recursos de amparo siempre que, por encima de posibles equívocos en el señalamiento de normas constitucionales, el derecho fundamental presuntamente violado se identifique con precisión..." (F.J. 5).

Recapitulando, en la situación actual: a) si un tercero ajeno a la Cámara invoca un derecho fundamental en un recurso de amparo, contra un acto de la Cámara, no cabe excepcionar la doctrina de los interna cor- 
poris; b) si un diputado invoca el derecho fundamental del art. 23.2 CE en un recurso de amparo, contra un acto de la Cámara, tampoco cabe excepcionar la doctrina mencionada.

Pues bien, si aceptamos - lo que quizás sea discutible- que lo específico de tal teoría consiste en que, constatado que un acto impugnado procede de un órgano parlamentario y proyecta sus efectos sólo sobre sus miembros, no ha de entrarse a examinar el fondo del asunto, entonces está claro que la doctrina de los interna corporis ha sido sustituida por la necesidad de ponderar, al entrar en el fondo del asunto, la necesaria autonomía de las Cámaras, o de las Cortes Generales, en cuanto órganos constitucionales. Si subsistiera tal doctrina, habría que aceptar que constatado que un acto es interno, no puede vulnerar un derecho fundamental. Con la primera rectificación indicada (tercero que invoca derecho fundamental) podría hablarse de una reformulación de la misma. Con la segunda, puede hablarse de su virtual sustitución por la ponderación de la autonomía del órgano constitucional.

Esto no quiere decir, como hemos visto, que todas las normas reglamentarias o constitucionales que reconocen atribuciones a los parlamentarios se integren en el bloque de la constitucionalidad del art. 23.2 (auto 12/86, F.J. 2), ni que hayan desaparecido los actos internos insusceptibles de control jurídico exhaustivo. En la Sentencia 161/1988 se hace un concienzudo examen para dilucidar si el derecho funcional alegado por los recurrentes es un derecho susceptible de ser incluido en el art. 23.2 CE.

IV. Habíamos señalado que las técnicas restrictivas con que los conflictos se configuraban en nuestro ordenamiento no podian evitar que éstos pugnaran por encontrar una solución jurisdiccional —en sentido amplio- por otros cauces.

Ahora estamos en condiciones de señalar algunos:

a) Frente a los actos y decisiones sin valor de ley de los órganos parlamentarios cabe, por parte de los parlamentarios, interponer el recurso de amparo por la vía del art. 42 LOTC: invocando el art. 23.2 CE e intentando concretar qué "derecho constitucional», susceptible de incluirse en dicho precepto, ha sido conculcado (vgr. Sentencia 161/1988).

b) Los actos normativos de órganos parlamentarios no impugnables por el art. 42 LOTC no pueden ser asimilados en su régimen de impugnación a los Reglamentos Parlamentarios, y son, por lo tanto, recurribles en inconstitucionalidad en virtud de una interpretación extensiva del art. 27.4.d) LOTC que acepta nuestro Tribunal (Sentencia 118/1988). Los parlamentarios individuales podrian impugnar los correspondientes actos 
de aplicación, y respecto de las normas correspondientes podría el Tribunal cuestionarse su constitucionalidad por la vía del art. 55.2 de la LOTC.

Se debe propugnar que además sean recurribles de modo directo cuando no necesiten actos de aplicación (voto particular del Magistrado Rubio Llorente en Sentencia 118/88).

Cabe plantearse si con ello se logra una satisfactoria sustitución de una regulación legal de los conflictos más amplia (como puede ser la alemana). Al respecto, quizás deba indicarse la existencia de lagunas:

a) Conflictos entre órganos de las Comunidades Autónomas.

b) Conflictos entre órganos distintos de los enumerados en el art. 59 LOTC (más art. 8 LOTCu): ya órganos internos de las Cámaras entre sí, o entre ellos y órganos externos (vgr., Comisiones de investigación).

c) Conflictos en que puedan ser parte los grupos, o más genéricamente, las minorías. Cabría preguntarse si los Grupos podrán invocar protección alegando el art. $23.2 \mathrm{CE}^{71}$. En la jurisprudencia constitucional puede encontrarse, en el ámbito de las Administraciones Locales, una protección de las minorias pero por medio del recurso de amparo de los individuos.

Es el caso de la Sentencia 32/1985, de 6 de marzo. Cinco concejales recurren en amparo frente a un Acuerdo de un Ayuntamiento que designaba a los componentes de Comisiones Informativas. Dicho acuerdo (v. F.J. 1), aprobado por siete votos favorables y cinco en contra, designa los componentes de manera tal que seis de los siete concejales que votaron en favor de la propuesta del Alcalde forman parte cada uno de ellos de, al menos, dos Comisiones distintas, en tanto que el restante es miembro de tres; en cambio, todos los concejales que votaron en contra participan en una sola Comisión, y además, todos ellos en la misma. El Tribunal anulb el acuerdo del Ayuntamiento y reconoció el derecho de los recurrentes a que cada una de las Comisiones Informativas del Ayuntamiento del que son concejales estén integradas de forma que se acomode a la proporcionalidad existente entre los distintos grupos políticos representados en el Ayuntamiento. Pero afirmó (F.J. 3) que los derechos (se refiere a los del art. 14 y el $23.2 \mathrm{CE}$ ) «los ostentan sólo las personas físicas o jurídicas, no los grupos políticos carentes de personalidad como son las fracciones políticas presentes en un organo colegiado».

71 V. J. BALLARIN: «El derecho de acceso a los cargos y funciones públicas», en Poder Judicial, n. ${ }^{\circ}$, págs. 53 y ss., quien entiende que la cuestión no está cerrada. 